Review Paper

\title{
Hybrid approaches coupling sol-gel and plasma for the deposition of oxide-based nanocomposite thin films: a review
}

\author{
Maria Mitronika $^{1}$ (D) Agnès Granier $^{1}$ (D) $\cdot$ Antoine Goullet $^{1}$ (D) Mireille Richard-Plouet $^{1}$ (D)
}

Received: 2 February 2021 / Accepted: 5 May 2021

Published online: 27 May 2021

(c) The Author(s) 2021 OPEN

\begin{abstract}
In view of developing new materials with enhanced properties, such as nanocomposite (NC) thin films, special interest has been given in optimizing the deposition processes themselves. The latter, if well selected, could give the freedom to control the NCs synthesis and final properties. Attempting to overcome severe challenges observed when creating NC or oxide-based NC film, hybrid approaches combining injection of colloidal solutions and plasma processes have

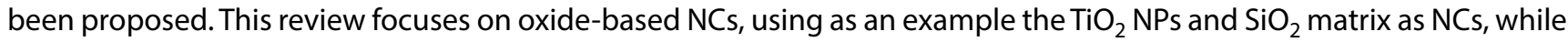
investigating their optical and dielectric properties. Additionally, this review presents the state-of-the-art in processes for the preparation of the NCs. The major categories of hybrid approaches coupling sol-gel and plasma processes are given. Finally, a comparative study among the published works is provided, aiming in highlighting the impact that each approach has on the physical and chemical characteristics of the produced NCs.
\end{abstract}

Keywords Oxides $\cdot \mathrm{TiO}_{2} \cdot \mathrm{SiO}_{2} \cdot \mathrm{Nanocomposite} \cdot$ Thin film $\cdot$ Deposition processes $\cdot$ Hybrid approaches

\section{Introduction}

Nanocomposites and nanostructured materials have gained the attention, as the properties of the resulting composite are likely to differ from the original bulk ones [1]. They are part of a more general category, the one of nanomaterials (NMs). Nanomaterial (NM) is defined as the "material with any external dimension in the nanoscale or having internal structure or surface structure in the nanoscale," with nanoscale defined as the "length range approximately from 1 to $100 \mathrm{~nm}$ " (ISO/TS 80,004-1:2015).

Nanocomposites are solid materials composed of at least two phases among which one exhibits nanoscale dimensions [1-3]. The definition of phase refers here to a medium for which no abrupt change in composition or density is observed. The surface-to-volume ratio due to the nanometric objects is very high, and their behavior becomes controlled by surface properties rather than by volume properties. In addition to this, the interactions between the interfaces of the phases become more important in terms of dimension and for the resulting property. Consequently, the materials can have novel chemical and physical properties that depend on the morphology and interfacial characteristics of the component materials. Since 1996 and based on a search in Web of Science using the keywords $\mathrm{TiO}_{2}, \mathrm{SiO}_{2}$ and $\mathrm{NCs}$ (carried out June $12,2020)$, nanocomposites have been an emerging field providing in an exponential rate many scientific works, reaching in 2019 a total amount of 15.790 records. Their applications are rather broad with some of the most predominant ones being the packaging, insulations, antimicrobial, antireflective, self-cleaning, solar cells, sensors, and optics [4-9].

Maria Mitronika, maria.mitronika@etu.univ-nantes.fr | 1 Université de Nantes, CNRS, Institut des Matériaux Jean Rouxel, IMN, 44000 Nantes, France.

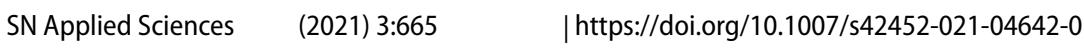


Due to the versatile configuration these two phase materials can have, some works focused in their theoretical study, using effective medium theories (EMT) $[10,11]$, volume averaging theory (VAT) [12] or the Lippmann-Schwinger equation [13]. Garahan et al. used the VAT model and finite elements to describe the boundary conditions of the nanoinclusion shapes, for the effective dielectric $(\kappa)$ and electrical properties and derived the effective index of refraction $n_{\text {eff }}$ and absorption index $k_{\text {eff }}$ of nanoporous materials. These results were used to predict the behavior of the optical properties of nanocomposite materials. It was found out that due to the presence of strongly absorbing dispersed phase such as metallic nanowires, the effective refractive index was much smaller than each of the two continuous or dispersed phases. Rao et al. [10], while comparing different EMTs for polymerbased $\mathrm{NCs}\left(\mathrm{TiO}_{2} \mathrm{NPs}\right.$, polymer matrix), stressed out that the use of the effective medium can hold only when the two phases are chemically independent (no chemical binding between the components). In addition, Lozovski et al. [13] indicated that the size of the nanoparticles or more generally the filler, the thickness of the nanocomposite and the distance the filler is located from the substrate can play a key role in the optical absorption of the NC. The aim of these studies was to render it possible through this theoretical analysis to predict the properties of the final $\mathrm{NCs}$, even if they were not implemented and characterized experimentally. In detail, it is proposed that knowing the tunable parameters that could affect the optical response (such as the filling factor, the nature of the NPs and matrix, the size and shape of the filler, the thickness of the NC) can provide the guidelines for the design of the NCs oriented for the targeted applications. Also, the way (linear, parabolic, etc.) that the optical response is managed could additionally provide such guidelines.

In this work, a review on the hybrid processes coupling sol-gel and plasma deposition techniques for the production of NC thin films is attempted. Initially, this review focuses on the interest oxide-based NCs can have, using as an example the $\mathrm{TiO}_{2} \mathrm{NPs}$ and $\mathrm{SiO}_{2}$ matrix. Subsequently, the major categories of hybrid approaches coupling sol-gel and plasma processes are given. Finally, a comparative study is provided, aiming in highlighting the impact that each approach has on the physical and chemical characteristics of the produced NCs.

\section{Oxide-based NC thin films: $\mathrm{TiO}_{2}$ NPs and $\mathrm{SiO}_{2}$ matrix}

In general, nanoparticles can be classified depending on their nature (for example, carbon-based, ceramic, metallic, polymeric and semiconductor NPs [14]), size, morphology, physical and chemical characteristics, etc. Among the different existing dielectric materials, $\mathrm{TiO}_{2}$, as high-K (dielectric constant $>80[8,9]$ ), stable and low-cost semiconductor has been identified as an ideal candidate for its electrical $[15,16]$, optical $[17]$, dielectric $[8,9]$ and photocatalytic [18] properties. Trying to expand these properties, $\mathrm{TiO}_{2} \mathrm{NPs}$ were extensively prepared in different configurations [19] and studied especially for cosmetic [20], antibacterial [21], solar cell [22-25], self-cleaning [26], hydrophobic [27] and dielectric-isolative [28] applications. Given the different properties that the nanoparticles can have compared to the bulk materials, we gathered in this paragraph the effect of nanostructuration on the optoelectronic properties: band gap, dielectric constant, optical index, and how they can be adjusted by preparing NC.

It is well known and often observed experimentally that when the diameter of the crystallite of a semiconductor (SC) particle falls below a critical radius of about $10 \mathrm{~nm}$, charge carrier behave quantum mechanically. As a result of this quantum confinement, as shown in Fig. 1a), the electron density of states of nanometric SC materials exhibits features which are intermediate between the situation of clusters, composed of discrete energy levels, and the one of periodic crystalline solids. Thus, the electron structure is composed of wide bands, namely the valence (VB) and conduction bands (CB) separated by the band gap. The quantum confinement in nanocrystalline $\mathrm{SC}$ induces a narrowing of $\mathrm{VB}$ and $\mathrm{CB}$, and consequently, this leads to the enlargement of the band gap. Those shifts of the band edges also introduce a modification of the redox potentials associated with these levels [29, 30]. Enright et Fitzmaurice [31] predicted the size dependence for the energy of the valence and conduction bands, which is given in Fig. 1b. Based on this, for anatase nanocrystallites below $10 \mathrm{~nm}$, a decrease in the band gap is observed. This decrease is more pronounced for nanocrystallite sizes below $5 \mathrm{~nm}$. Above the value of $10 \mathrm{~nm}$, the band gap is expected to have similar behavior as the bulk material. A sensitive tool to follow the anatase nanocrystallite sizes is Raman spectroscopy, and attempts to correlate the size of the $\mathrm{TiO}_{2}$ crystallite with the Raman shift were carried out by Pighini et al. [32].

Regarding the dielectric characteristics $\mathrm{TiO}_{2} \mathrm{NPs}$ can have, in comparison with bulk materials or different NPs diameter, the work of Zhang et al. [33] was one of the earliest reports. As shown in Fig. 2, the real part of the dielectric constant $\varepsilon_{r}{ }^{\prime}$ was measured in a frequency range of $10^{1}-10^{5} \mathrm{~Hz}$.

Different size of anatase nanoparticles was used and was compared with $\mathrm{TiO}_{2}$ anatase coarse grains with a size of $\sim 1 \mu \mathrm{m}$. The results indicated that in this frequency range, the dielectric constants of $\mathrm{TiO}_{2} \mathrm{NPs}$ have equal or larger values than the coarse grain anatase $\mathrm{TiO}_{2}$. In 


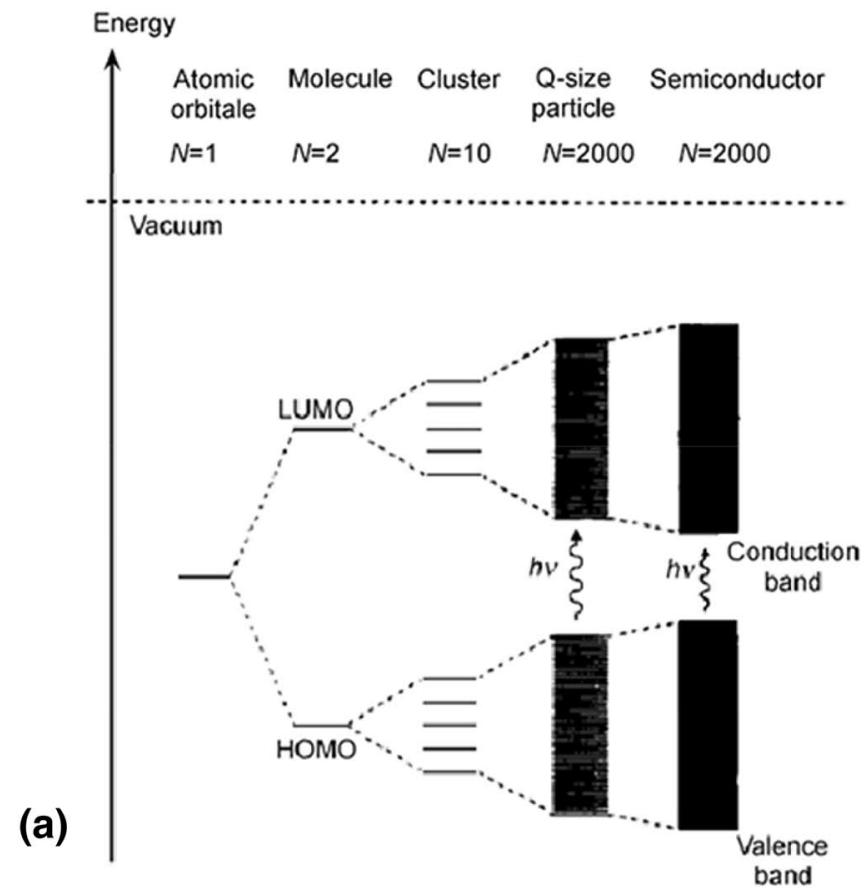

Fig. 1 a Molecular orbital (MO) model for particle growth of $\mathrm{N}$ monomeric units. The spacing of the energy levels (i.e., density of states) varies among systems. Reproduced with permission from [29], copyright 1995 ACS Publications. On the left-hand side of the scheme the bands of Q-size particles become narrower compared

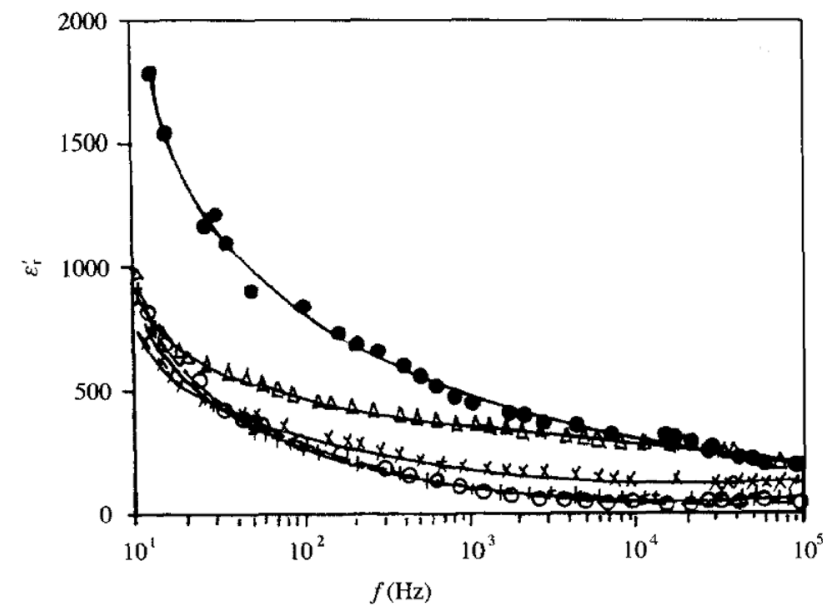

Fig. 2 Spectra of dielectric constant as a function of the frequency $f$ at room temperature for nano- $\mathrm{TiO}_{2}$ with various particle diameters d. Anatase: (o) $\mathrm{d}=9.8 \mathrm{~nm},(\dot{\triangle}) 14.4 \mathrm{~nm},() .17.8 \mathrm{~nm},(\mathrm{x}) 28.5 \mathrm{~nm},(+)$ coarse grains $(\sim 1 \mu \mathrm{m})$. Reproduced with permission from [33], copyright 2006 John Wiley and Sons Publishing

addition to this, for larger diameter size (in the nanometer range) a higher value is observed especially in the low frequencies. In this frequency range, this effect originates from the polarization of the dielectric materials

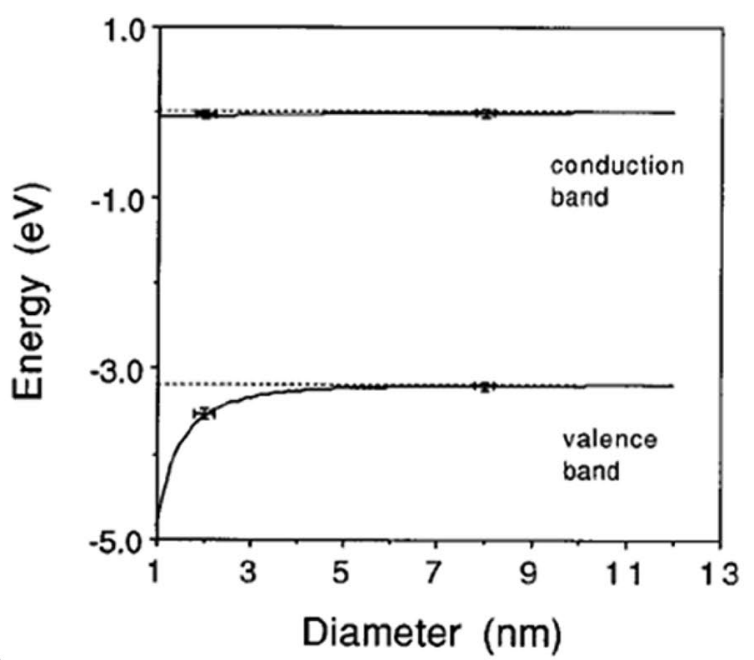

(b)

to the bulk semiconductor. $\mathbf{b}$ Theoretical prediction of the Eg band gap as a function of the particle radius. With bars, the experimentally determined changes in the energy of the valence and conduction band edges are plotted. Reproduced with permission from [31], copyright 1996 ACS Publications

based on interfacial and space charge mechanisms. Hence, under the action of an external electric field, positive and negative space charges in the interfaces move toward negative and positive poles of the electric field, respectively. As a consequence, for coarse-grain $\mathrm{TiO}_{2} \mathrm{NPs}$ (large domains), the number of interfaces is very small and the space charge polarization becomes too weak to have an impact. Contrary to this, for small nanoparticles (nanometer range), the volume fraction of interfaces is much larger, so that the contribution of space charge polarization in interfaces to $\varepsilon_{r}^{\prime}$ becomes large enough to enhance the dielectric constant. These findings were later verified by other authors [34-36]. Specifically, it was observed that for several materials such as aluminum oxide, titanium oxide and silicon dioxide, the relative dielectric constant is 10 times higher for the nanoparticles in powder compacts than for the bulk materials [36].

Conventional dielectric materials are ceramics with large dielectric permittivity, coupled with high stiffness and excellent thermal stability. However, their applicability for passive components such as capacitors is largely impeded by their small breakdown strength and challenging processing conditions. Observing that these materials can exhibit enhanced characteristics in the nanoscale, attempts were carried out to disperse them as fillers in 
matrix materials. The aim was to capitalize the high permittivity of such nanoparticles with the good electrical strength of the matrix resulting in the creation of nanocomposites with novel properties. Many works use polymer matrices as they exhibit high electrical strength, flexibility and can be easily processed [37]. The drawback of these polymer matrices is that they lack in transparency or in high mechanical strength. Therefore, inorganic matrixes such as silica are a good alternative as they can exhibit significant isolative properties (high electrical strength), high mechanical strength and optical properties such as transparency in a broad spectral range.

Since 2014, approximately 892 publications including the keywords of $\mathrm{TiO}_{2}, \mathrm{SiO}_{2}$ and nanocomposites have been reported. The most cited applications of these works are regarding photocatalytic and antibacterial or dielectric and optical applications. Focusing mainly on the $\mathrm{TiO}_{2}-\mathrm{SiO}_{2}$ nanocomposites $\left(\mathrm{TiO}_{2} \mathrm{NPs}\right.$, $\mathrm{SiO}_{2}$ matrix), Sarkar et al. [38] attempted to investigate the $\mathrm{TiO}_{2}-\mathrm{SiO}_{2}$ nanocomposite thin films elaborated by sol-gel. In this specific work, the size of the nanoparticles was varied from $\sim 1$ to $22 \mathrm{~nm}$. At the same time for the larger NPs, a higher concentration of the Ti content was successfully achieved. Current density-electric field (J-E) measurements showed that for all the NPs sizes an ohmic conduction is observed in the low field. However, depending on the size of the $\mathrm{TiO}_{2} \mathrm{NPs}$, their low field resistivity was found to decrease by a factor of $10^{2}$ (from $2.210^{12}$ to $2.210^{10} \Omega \mathrm{cm}$ ) for the larger sizes. The explanation given by the authors was that in these cases a percolated network of $\mathrm{TiO}_{2}$ nanoparticles is created, controlling its conductivity. For higher electrical fields, as expected all compositions exhibit space-charge limited behavior. For the nanocomposite with NPs sizes as low as $\sim 1 \mathrm{~nm}$, some oscillations were observed and this phenomenon was attributed to the single electron tunneling effect (SET) caused by the small nanocrystallites isolated inside the amorphous silica matrix having a wide band gap.

In recent years apart from studying the electrical response of such nanocomposites, nanoparticles have also been used to make transparent nanocomposite structures having high refractive indices. If the NPs are small compared to the wavelength of light, scattering is avoided, and the nanocomposites are transparent even at high nanoparticle filling factors. Hence, it is possible for the refractive index to be tuned over a wide range by changing the filling factor and type of filler $[12,39,40]$. Following this direction, Kermadi et al. examined the optical characteristics of sol-gel-derived $\mathrm{TiO}_{2}-\mathrm{SiO}_{2} \mathrm{NCs}$ with varying composition. The size of the $\mathrm{TiO}_{2} \mathrm{NPs}$ was between $4 \mathrm{~nm}$ for low fraction of $\mathrm{TiO}_{2}$ in the $\mathrm{NC}$ and increased up to $10 \mathrm{~nm}$ for higher compositions. Using ellipsometry and Lorentz-Lorentz effective medium approximation this author showed that as the fraction of $\mathrm{TiO}_{2}$ increases the refractive index, and in addition, the porosity of the film increases [41, 42]. In a similar way, Lopes de Jesus et al. [43] investigated both the porosity and the effective refractive index of the films using sol-gel-derived $\mathrm{TiO}_{2}-\mathrm{SiO}_{2} \mathrm{NCs}$. Using Bruggeman effective medium approximation, it was possible to show the modulation of the refractive index (from 2.08 to 1.44 at $\lambda=633 \mathrm{~nm}$ ), by varying the composition of the NC or its thickness (layered deposition with dip casting).

Based on these findings, the ability to choose the nature of the nanoparticles and more importantly their filling factor and size in the matrix is of great interest, as both the electrical and optical characteristics of the nanocomposite can be tuned in a controlled manner.

\section{Processes for the preparation of nanocomposite thin films and nanomaterials}

One of the most significant challenge in the development of such nanocomposites is the control of the growth mechanisms, the final morphology and the spatial distribution of the nanoparticles using reproducible, versatile and low-cost processes. Since nanocomposites and nanomaterials are an emerging scientific and industrial field, several approaches enable their production. A good discrimination could be the bottom-up and top-down ones [44].

In this section, we have decided to separate the processes for the creation of nanomaterials in three general categories: approaches involving the precursors to be processed in (i) the liquid phase, (ii) the gas phase and (iii) both the liquid and gas phases. We denote the latter process the hybrid approach since it is coupling the two previous ones.

\subsection{Liquid-phase processes}

The term "liquid phase" is used, to describe the condition when wet chemistry is carried out for the fabrication of the nanomaterials. One of the most widely used process for the creation of nanomaterials is sol-gel. The sol-gel process is a chemical synthesis that starts from an ionic or a molecular compound and forms a three-dimensional network through oxygen or hydroxyl bond formation between the ions and the release of water or other small molecules. Some advantages of this technique are the low temperature during the process, the widely used precursors and the reproducibility. On the other hand, when drying (to create nanocomposite films), nanoparticles may be released arising several toxicity issues $[20,36]$. In case films are targeted, drying needs to be perfectly controlled in order to avoid cracks. 
In more detail, sol-gel process is a chemical method which is based on hydrolysis and condensation reactions [44-47]. With the correct amount of reactants, nanosized particles nucleate. There are three basic steps in the sol-gel process: a) the partial hydrolysis of the reactant that can be metal alkoxides (a widely used precursor given as an example here) to form reactive monomers, b) the condensation of these monomers to form colloid-like polymers (sol formation). At this step, the hydrolysis and condensation reactions lead to the formation of solid particles that are suspended in the liquid, a so-called sol. Depending on the surface charge of the objects, the sol is stable if the zeta potential lies above $30 \mathrm{mV}$ in absolute values. As the third step, the particles contain on their surface groups still active in condensation steps, and therefore, they crosslink to a gel. The latter is defined as a solid network that contains liquid in its pores [48]. The last step involves drying the gel. Consolidation can be obtained by annealing at high temperature if densification is needed to lead either to films, fibers or powders.

Figure 3 shows schematically all the steps needed to acquire a nanomaterial through sol-gel. As this technique has been investigated since the middle of the nineteenth century [49], there have been, as expected, numerous reports. Focusing on the materials of interest, meaning $\mathrm{TiO}_{2}$ and $\mathrm{SiO}_{2}$, such reports target mainly on their photocatalytic [50-54], antireflective [24, 53, 55], hydrophobic $[56,57]$ and dielectric $[38]$ properties. To attain the final nanocomposite, three main experimental processes were followed. There are preparation of two different sols and the mixture of them $[24,51,52,58]$, the preparation of $\mathrm{TiO}_{2}$ sol and the mixture with an alkoxide such as tetraethoxysilane (TEOS- $\mathrm{SiO}_{2}$ precursor) [55-57] or the mixture of $\mathrm{TiO}_{2}$ NPs inside the TEOS precursor [54]. The deposition of the produced nanocomposite sol-gel is taking place through spin coating, dip casting or drop casting.

\subsection{Gas-phase processes}

The term "gas phase" is used, to describe the state of the precursors in these processes being in a vapor or initially solid state inside the reactor/system.

Fanelli and Fracassi divided these processes in three categories. First, systems that use the same chemical source and strategy for the creation of NCs. This could be for example one plasma-enhanced chemical vapor
Fig. 3 Different sol-gel process steps to control the final morphology of the product. Adapted from $[59,60]$
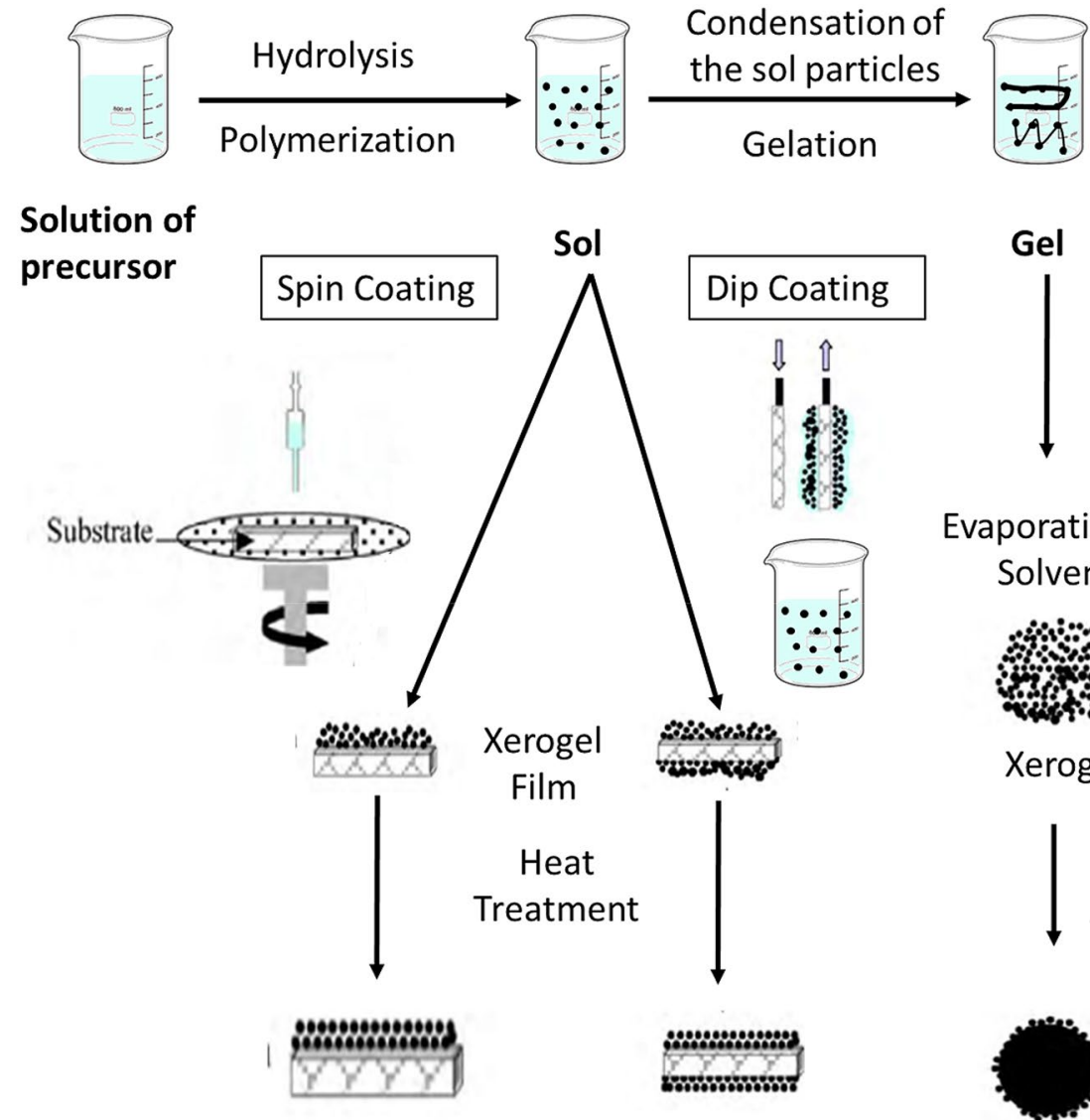

Evaporation of Solvent
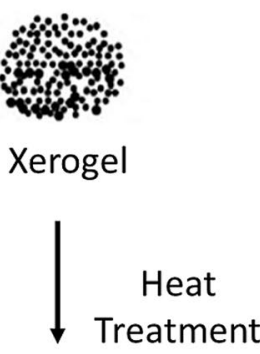

Dense Film 
deposition (PECVD) system using a mixture of precursors. This may lead in the production of mixed oxide onephase films, rather than a nanocomposite. In case these processes take place separately, then for instance $\mathrm{TiO}_{2}$ NPs could be deposited through atmospheric pressure plasma-based systems [61-64] and $\mathrm{SiO}_{2} / \mathrm{SiOX}$ matrices through low-pressure plasma-based ones [65-69]. Second, the deposition using two independent chemical sources with one strategy such as co-sputtering [70], or co-evaporation [71]. Finally, the third category, where separated strategies and different sources are being followed. Over the last years, this category was proven more versatile in regard to the nature of the NPs and the matrix, thus focusing more the attention of the scientific community. Hence, for the elaboration of nanocomposite films through this category of processes, a combination of deposition systems is used for the simultaneous or step-by-step creation of the NPs and the matrix. For instance, in the past, several works involved the combination of physical vapor deposition (PVD) and the plasma-enhanced chemical vapor deposition (PECVD) for the simultaneous deposition of the NPs and the matrix accordingly [72-75]. For the deposition of the NPs, sputtering-deposition techniques have been utilized such as
DC glow discharges, capacitively coupled RF discharges, DC/RF magnetron plasma sources. Typical examples of successfully developed films consisting of metallic (e.g., $\mathrm{Ag}, \mathrm{Au}, \mathrm{Pt}, \mathrm{Ti}$ ) or metal oxide (e.g., $\mathrm{SiO}_{2}, \mathrm{TiO}_{2}, \mathrm{ZnO}$ ) NPs embedded in a large variety of polymeric matrices have been reported through these approaches [39].

More recently, gas aggregation nanocluster sources (GAS) have been used for the preparation of metal [76-82] or metal oxide nanoparticles such as $\mathrm{TiO}_{2}$ ones [83-86], mainly based on vacuum metal evaporation or magnetron sputtering. This takes place in an aggregation chamber enclosed by an orifice through which the expanding gas (usually an inert gas such as $\mathrm{Ar}$ or $\mathrm{N}_{2}$ ) carries the clusters into the low-pressure deposition chamber (typically ultrahigh vacuum one) [87]. This process can then be used for the synthesis of the matrix using for instance plasma processes or using another magnetron configuration to create core-shell nanoparticles.

An example of gas-phase approaches is given in Fig. 4 . In this figure three different experimental strategies are followed for the creation of Ag/plasma polymer nanocomposites: in Fig. 4a, the simultaneous sputtering and plasma polymerization of the NCs, in Fig. $4 \mathrm{~b}$ the deposition of the NCs from two independent magnetrons (having
Fig. 4 Different approaches for the production of $\mathrm{Ag} /$ plasma polymer nanocomposites: a simultaneous sputtering and plasma polymerization, $\mathbf{b}$ deposition from two independent magnetrons and $\mathbf{c} a$ combination of a gas aggregation source and plasma polymerization. Reproduced from [88], open source MDPI Publishing
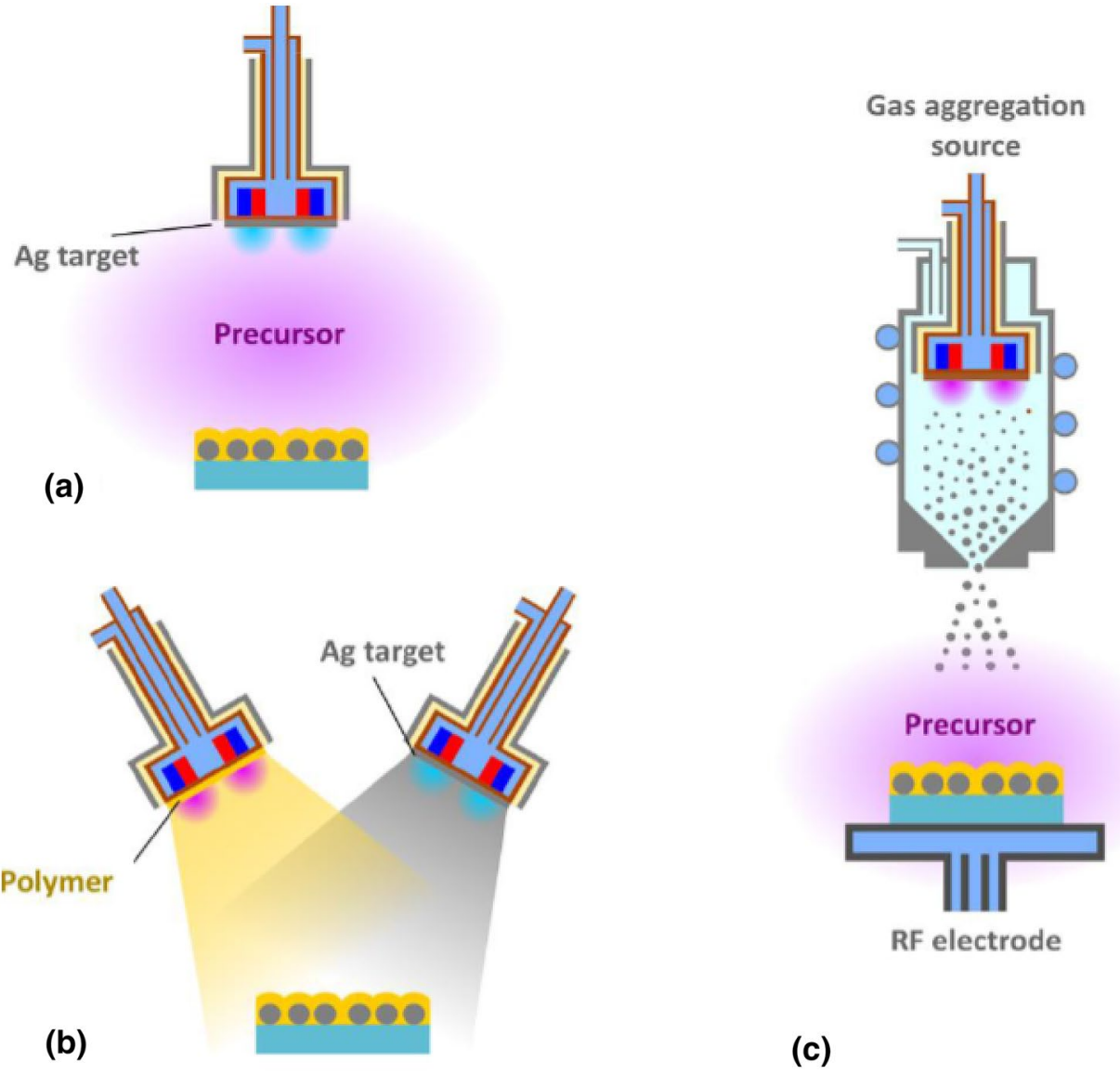

(c) 
the possibility to adjust the experimental conditions/characteristics both of the NPs and the matrix) and in Fig. 4c a combination of a gas aggregation source and plasma polymerization.

Some appealing characteristics of these gas-phase approaches are the high purity of the synthesized NPs and the environmentally friendly character (since no solvent or liquid precursors are needed). Contrary to that, the control of the NPs' characteristics is dependent on the system parameters with a small freedom for parameterization.

\subsection{Hybrid approaches coupling liquid- and gas-phase processes}

Several liquid- and gas-phase processes aim in the elaboration of nanomaterials or nanocomposite thin films. The drawback of liquid-phase processes such as sol-gel is related to its multiple steps until acquiring a nanocomposite thin film as well as the toxicity that the NPs can have during the drying of the film [44]. Moreover, through gas phase processes, it has been shown that a combination of vacuum techniques is being used. This allows the simultaneous creation of the nanoparticles and optionally the matrix without the actual manipulation of the nanoparticles by the user. Unfortunately, the size, form and other parameters of the produced nanoparticles are difficult to control.

Hence, recently, an increasing trend has appeared from the scientific community aiming to the production of nanomaterials or nanocomposite thin films, by combining liquid- and gas-phase processes. This is attempted by creating an aerosol of the NPs colloidal solution or directly injecting the colloidal solution inside a gas-phase system. The flexibility offered by aerosol-assisted deposition processes, in respect of those in which NPs are generated in situ, mainly resides in the possibility of using many preformed NPs in combinations with any compatible conventional precursor [39].

The challenging part in approaches like these mainly lies in the droplet or aerosol production. Hence, a specific system will be needed to allow this droplet production in atmospheric or low-pressure gas-phase systems. Thanks to the spray drying $[89,90]$ techniques, spray pyrolysis [91-93] or analytical techniques, such as inductively coupled plasma optical emission spectrometry and mass spectrometry (ICP-OES, ICP-MS) [94-98], the adaptation of these systems could be possible. Several droplet generation techniques exist involving different driving force to assist the droplet formation such as vaporization, pressure, centrifugation, electrostatic forces and ultrasonic atomization [89].

In this section, these hybrid configurations will be introduced, being categorized by the working pressure of the gas process system (atmospheric or low pressure). At the end of this section, an accumulative table with the hybrid approaches used and the film characteristics will be given in order to make a qualitative assessment of the produced films.

\subsubsection{Atmospheric pressure-based systems}

Several attempts have been published over the past ten years aiming in the deposition of either nanoparticles only or nanocomposite thin films using hybrid approaches. In this part, some of the atmospheric pressure configurations will be analyzed along with their injection system. Three main categories were reported in the literature: The Suspension Plasma Spray, the systems using non-equilibrium atmospheric pressure Plasma Jets and the ones using dielectric barrier discharges (DBD).

Regarding the first category, the Suspension Plasma Spray [99-102] utilizes the high-temperature and highvelocity plasma jet to melt and spray nanometer-sized nanoparticles. Each drop of the liquid stream is fragmented into droplets (<a few $\mu \mathrm{m}$ ), which, after vaporization of the liquid phase, result in nano- or sub-micrometer-sized melted or partially melted particles, forming nanostructured coatings [101]. This process resembles the one of spray pyrolysis with the difference that the heat comes from the plasma (temperature up to $10,000 \mathrm{~K}$ ) and not from a furnace. The resulted films have a melted like appearance with polydispersed in size-deposited particles.

Moreover, the approaches using non-equilibrium plasma jet configuration usually involve a system where the working gas along with the matrix precursor and the nebulized liquid is fed to the plasma jet [103-105]. For instance, as described by Liguori et al. [105] and given schematically in Fig. 5, at the same time the solution containing NPs is injected into the plasma source through the primary channel. Simultaneously, a second flow of Ar is introduced in a nebulizer system containing the dispersion of Ag NPs in ethanol (EtOH). The so-formed aerosol is injected into the plasma source through the secondary gas channel. The resulted films were polymerized polyacrylic acid (pPAA) and silver nanoparticles (around $100 \mathrm{~nm}$ in size) having antimicrobial applications, a SEM image of which can be seen in Table 1 [90].

Since 2006 many reports involve the dielectric barrier discharge (DBD) systems, for the injection of the colloidal solution and the deposition of nanomaterial thin films [39, 106-114]. For the efficient preparation and injection of the liquid solution containing NPs, two main systems were used, which are the nebulizer and the atomizer. In the case of the nebulizer, the flow rate of the colloidal solution is fed to the nebulizer through its regulation by a syringe pump. There the carrier gas for the production of the 
Fig. 5 Experimental setup of the plasma co-deposition process. Reproduced with permission from [105], copyright 2015 John Wiley and Sons Publishing

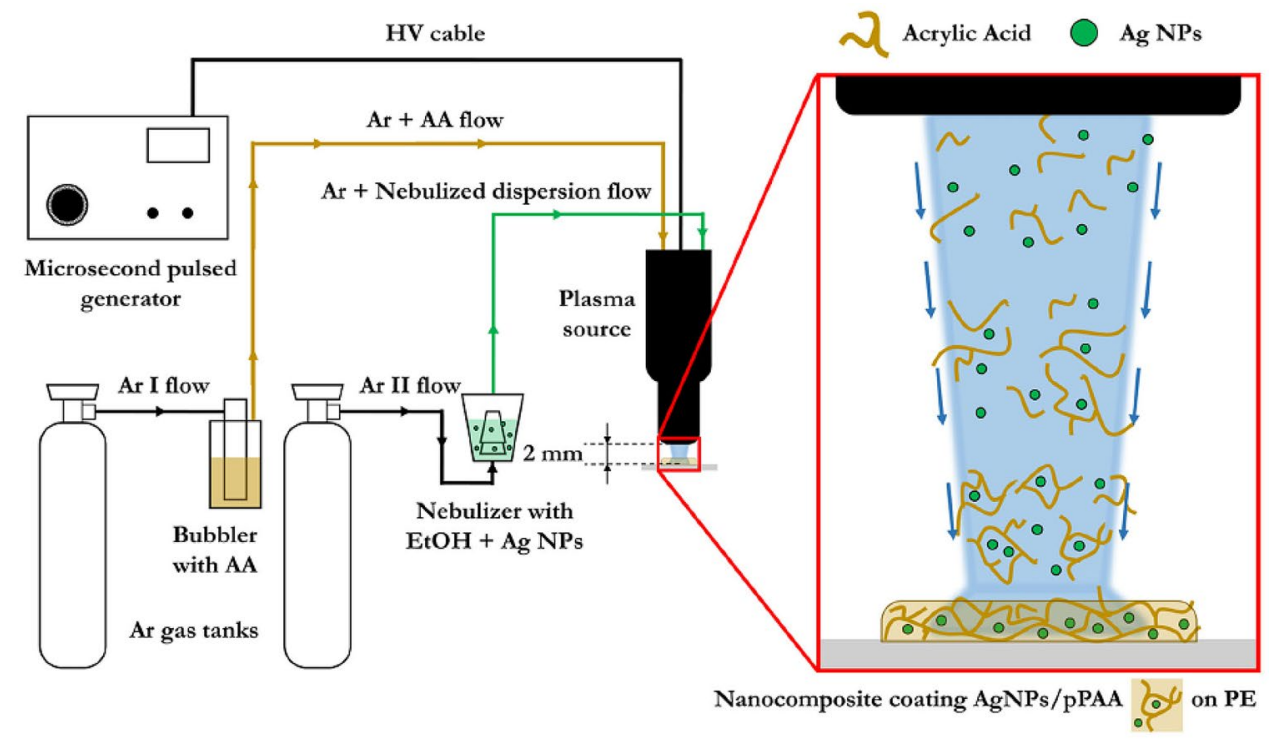

aerosol is introduced, and based on the Venturi effect, an aerosol is generated at the outlet of the nebulizer [115]. In the case of the atomizer, compressed air expands through an orifice to form a high-velocity jet. At the same time, the liquid is drawn into the atomizing section through a vertical passage and is then atomized by the air jet [116]. Recently, using a DBD system with a nebulizer, Profili et al. [110-113] reported several experiments for the deposition of nanocomposite thin films using the DBD reactor given in Fig. 6. This group attempted the deposition of $\mathrm{TiO}_{2}$ NPs only or nanocomposite thin films through various approaches such as dissolving the NPs inside the hexamethyldisiloxane (HMDSO) liquid and injecting it in the system (see Table 1, Ref 96 for the SEM images) or in a twostep approach injecting first the colloidal solution of NPs (see Table 1, Ref 95 for the SEM images) and second the $\mathrm{SiO}_{2}$ matrix (introducing the vapor in the plasma).

\subsubsection{Low-pressure-based systems}

A small number of scientific reports have been published involving low-pressure physical systems. This could be due to the fact that handling of aerosols or liquids at low pressure is challenging. These challenging conditions can be for instance the reactor contamination, especially when working at room temperature, the degradation of the turbopump lifetime and plasma perturbation (if there is use of plasma) due to pressure variation caused by the solvent vaporization $[39,117]$. Two main categories will be given here, the thermally activated vacuum techniques such as the chemical vapor deposition (CVD) and the ones based on PECVD. Due to the scope of this work, the main focus will be given at the low-pressure plasma systems used and their configuration to produce nanomaterials through this hybrid approach.

Some works involve the combination of the CVD systems with a direct liquid injector to produce nanomaterials [118-120]. An example of the configuration based on the direct liquid injection of the solvent containing nanoparticles is given in Fig. 11a.

As observed in this scheme (Fig. 7a), the injector has been positioned at the top of the reactor facing the rotating substrate holder which is heated at $150^{\circ} \mathrm{C}$. This results in the deposition of gold nanoparticles whose size was found to depend on the flow rate of the injected solution (containing NPs). AFM scan of the deposited gold nanoparticles is given in Table 1, [105]. The gas used for this approach was $\mathrm{N}_{2}$, in order to avoid any reactions with the gold NPs. In Fig. 7b a detailed diagram of the injection system is given, being comprised of an atomizer and a heated chamber. This allows the production of the aerosol with the help of a carrier gas.

Additional works have been found using a similar direct liquid injection (DLI) system for CVD [121-123] and atomic layer deposition (ALD) $[124,125]$ systems but without though the presence of nanoparticles in the injected liquid. They only capitalize the DLI process to atomize the injected liquid, vaporize it and generate the reactive vapor.

The first report using a low-pressure plasma system, aiming at the simultaneous injection of the NPs in a solution and the injection of the matrix precursor using the PECVD technique, has been proposed by Ross et Gleason [126] in 2006. These authors report that the atomization of the solution is accomplished by a $40 \mathrm{kHz}$ ultrasonic atomizer (Sonics and Materials, model VC134-AT with custom probe) located at the top of the reactor. The ultrasonic atomizers are based on the vibration of a quartz at high 


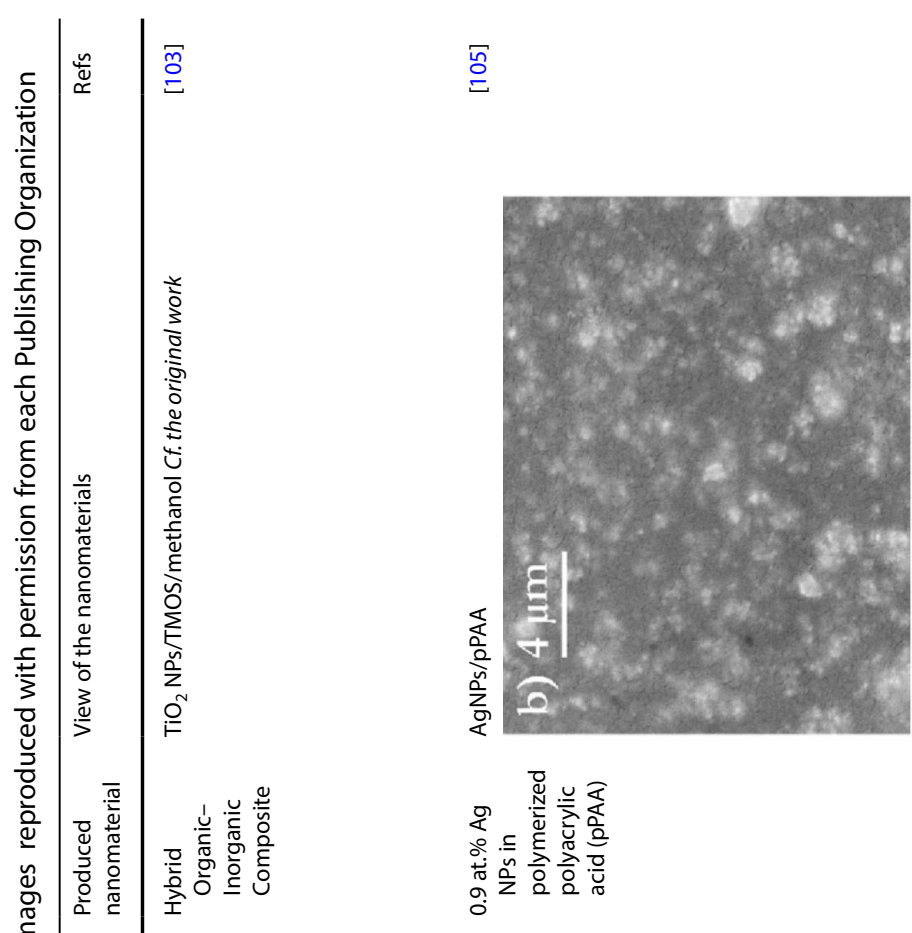

$\stackrel{\square}{\Xi}$

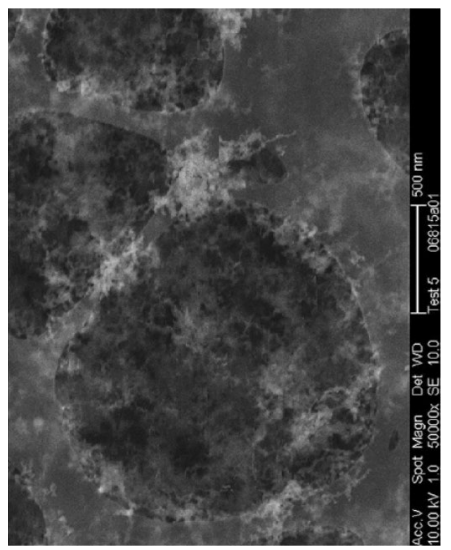

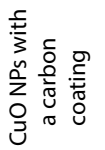

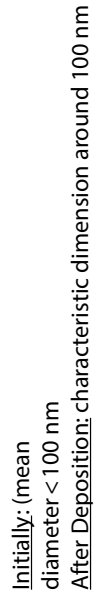

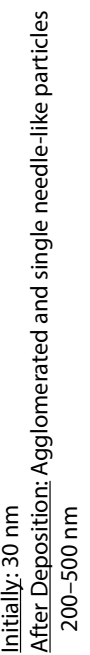

言

哀

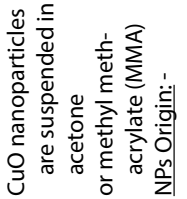

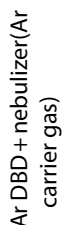




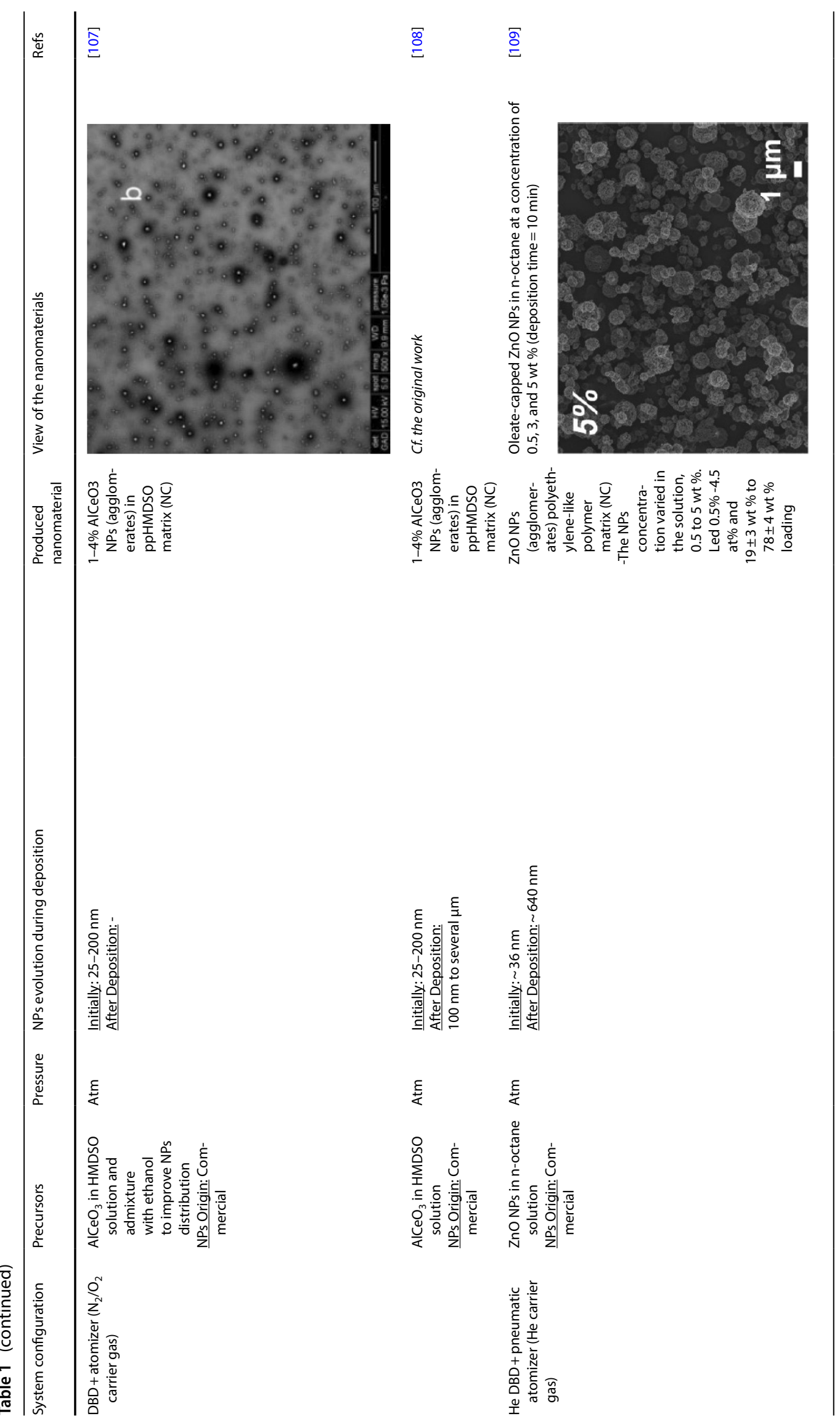

SN Applied Sciences

a SPRINGer Nature journal 


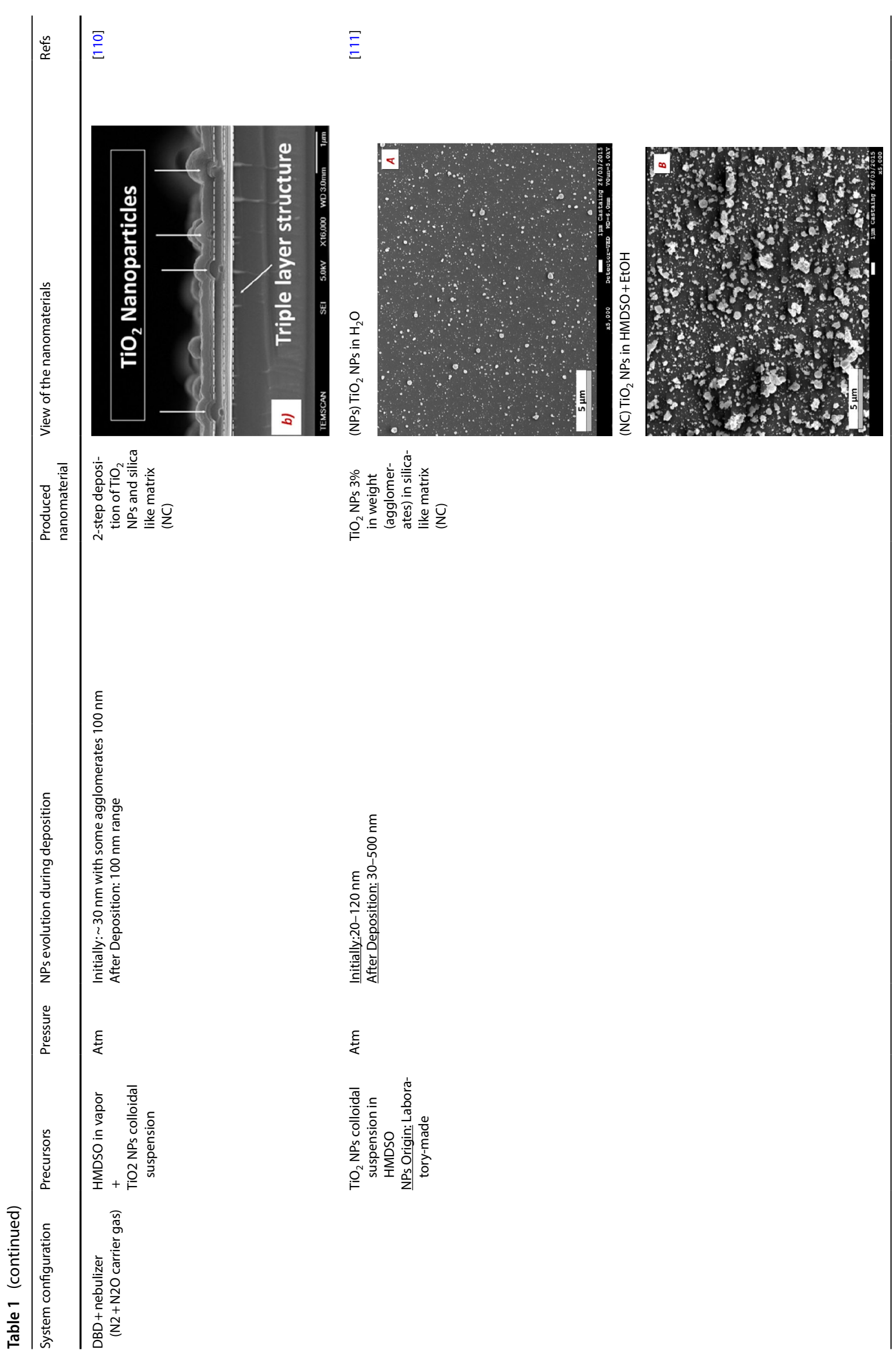




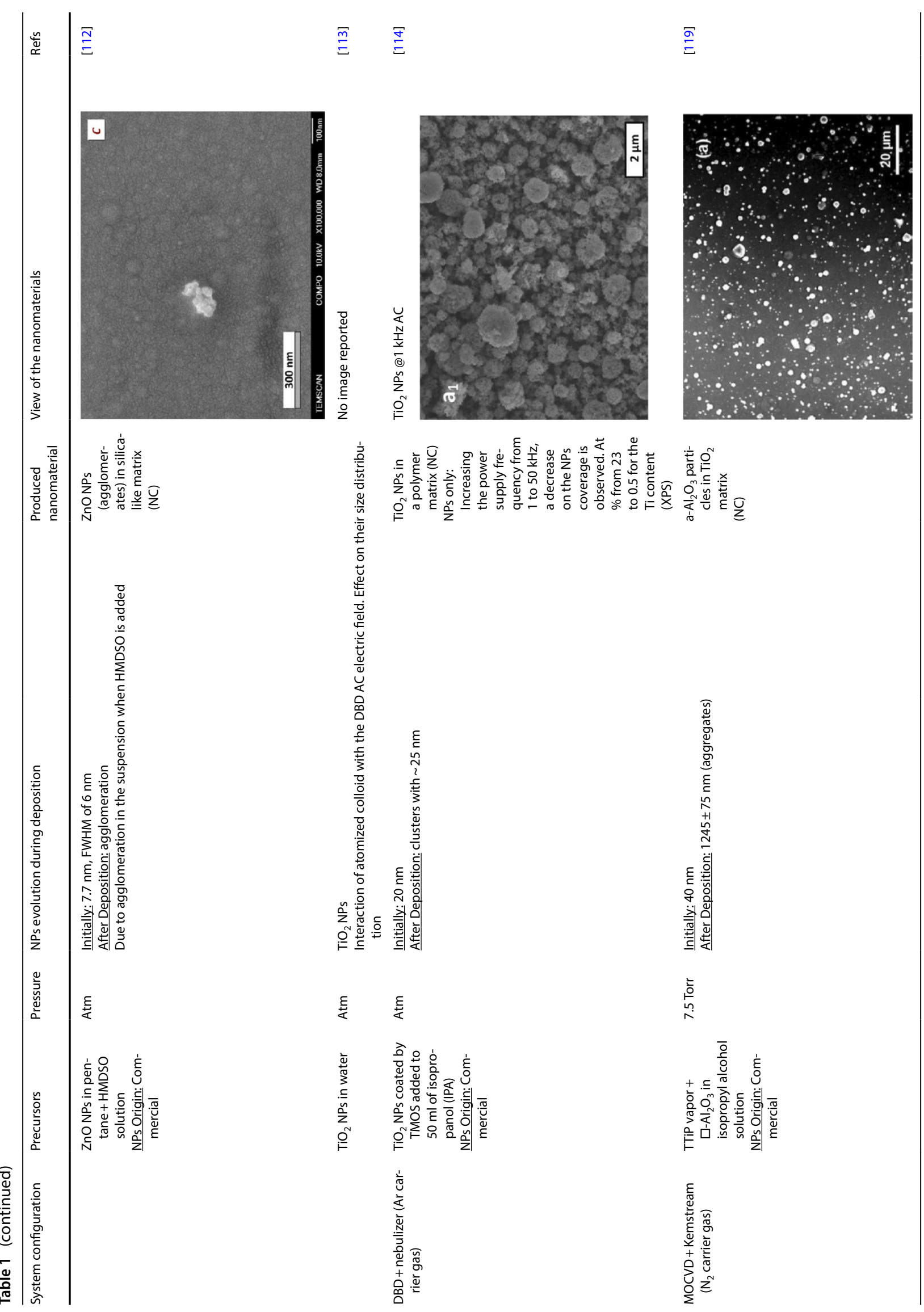

SN Applied Sciences 


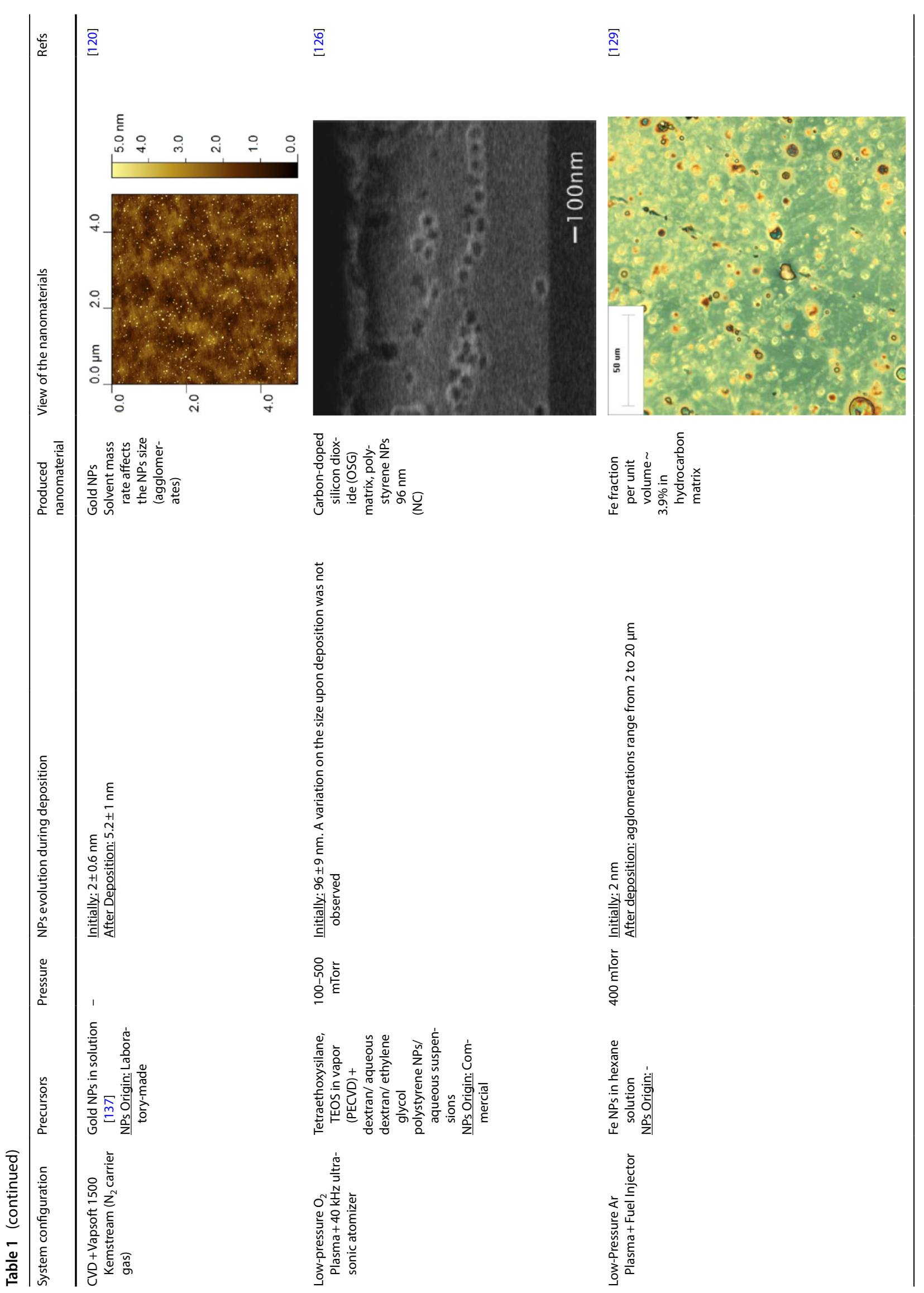




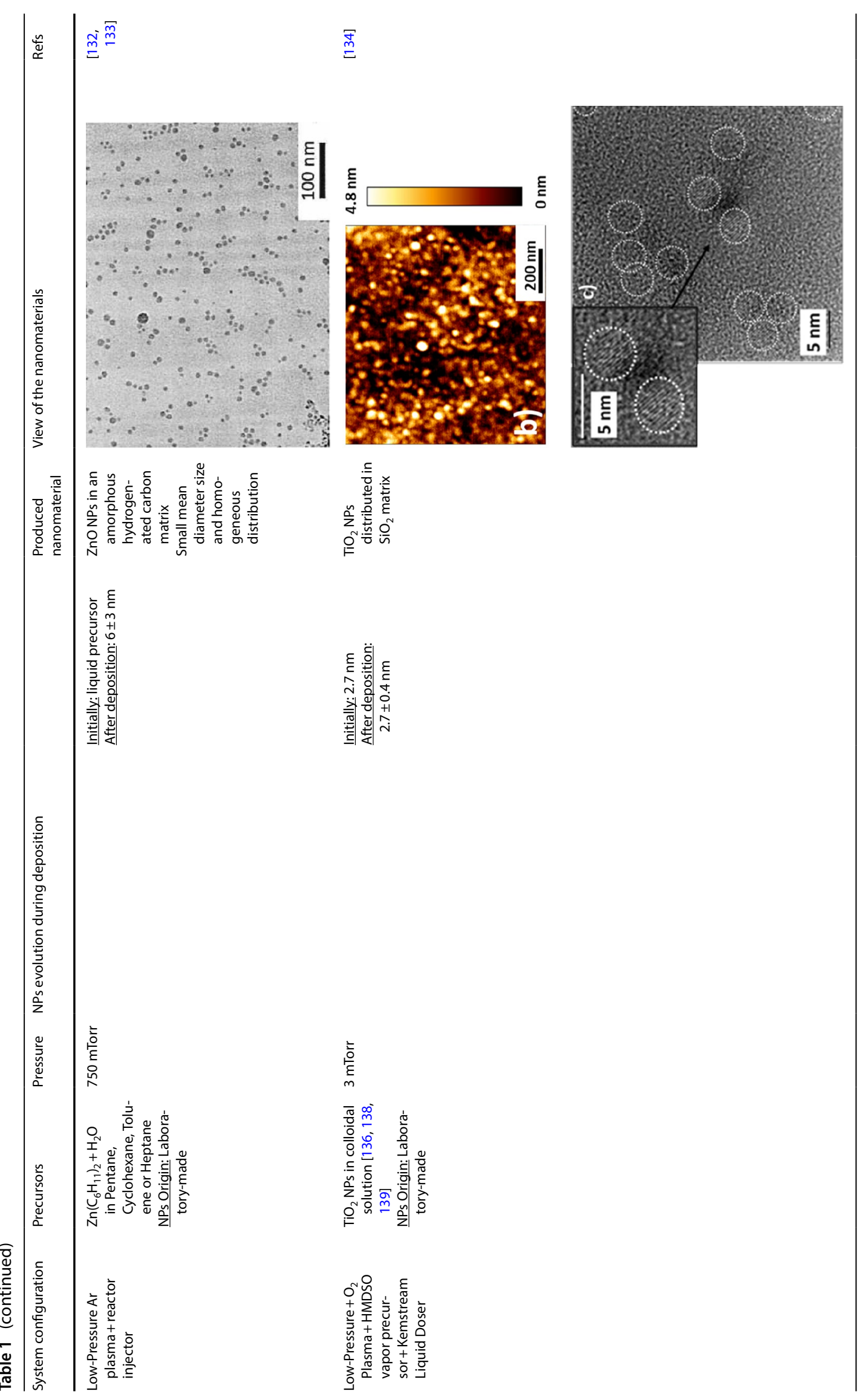

SN Applied Sciences 


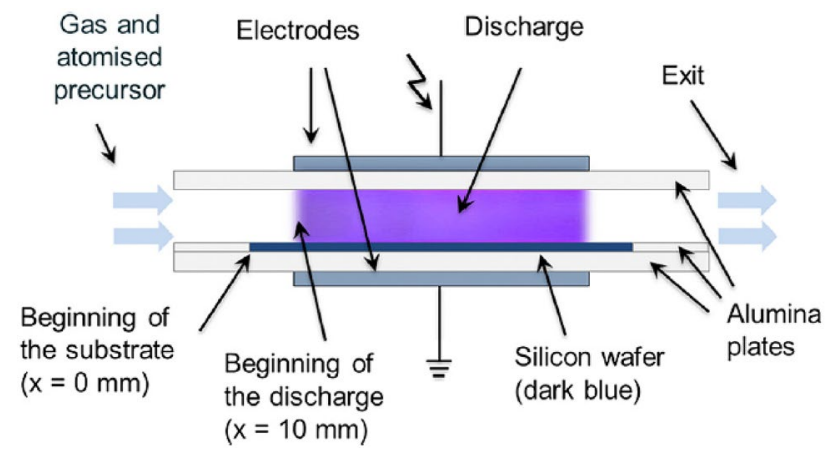

Fig. 6 Schematic of the dielectric barrier discharge reactor used for the growth of nanocomposite thin films in the works [110-113]. Reproduced with permission from [111], copyright 2016 AIP Publishing

frequencies, typically 1-4 MHz. Vibrations created cause the surface liquid film to burst into very fine droplets. However, these devices are used in the case of a large flow of suspension. Through a distribution ring, the matrix precursor (HMDSO) was introduced inside the reactor. The produced plasma was created using $\mathrm{O}_{2}$ as a working gas and an RF power supply as shown in Fig. 8.

The plasma was pulsed at an on-off rate of 10-40 ms, with a peak power of $300 \mathrm{~W}$. For the deposition, the pressure was maintained between 100 and 500 mTorr. The resulting films were polystyrene nanospheres with $96 \mathrm{~nm}$ diameter embedded inside the carbon-doped silicon dioxide matrix (see Table 1, [111]). An interesting observation from this work was the appearance of droplets formed at the surface of the film. Hence, the first attempts investigating how the volatility of the solvents can improve this phenomenon were established using water, ethylene glycol and labeled dextran (for fluorescent microscopy).

Three years later, in 2009, Ogawa et al. [127] reported a complete experimental study of directly introducing the liquid inside the low-pressure Ar capacitively coupled plasma (CCP) powered by an RF power supply (Fig. 9). This was established using a Denso fuel injector (23,209-0D040) in a pulsed mode and a produced droplet diameter estimated at $50 \mu \mathrm{m}$. The deposited Fe nanoparticles (brown rings) using this approach can be seen in Table 1, [114].

Furthermore, as discussed in a relative recent review of Bruggeman et al. [117] on plasma-liquid interactions, both the impact of the plasma to the droplets and vice versa has been poorly understood and studied. Ogawa's study was the first attempt to refer to the term "misty plasmas," being plasmas that contain liquid droplets. This term was first proposed by Coppins $[130,131]$ in 2004. Coppins stated also that these misty plasmas would not differ significantly from the dusty plasmas (plasma containing millimeter to nanometer particles) but that the liquid state of the droplets could allow droplet deformation and make surface tension forces more important. On this basis, Ogawa attempted the creation of a model describing the energy fluxes entering and exiting the droplet under the specific plasma conditions. Using this model and the energy balance equation he was able to determine the parameters affecting the droplet evaporation in this low-pressure medium. Finally, in a following work [128] he investigated the transient effects caused by the liquid injection on the same low-pressure plasma.

Recently, Clergereaux's group $[132,133]$ reported a new safer-by-design method for NC thin-film plasma deposition. This method allowed them to synthesize NPs from organometallic precursor in the reactor-injector prior to their injection in the RF low-pressure (750 mTorr) plasma reactor. The resulted nanocomposites consisted of small $(6 \pm 3 \mathrm{~nm})$ and isolated (i.e., non-aggregated) $\mathrm{ZnO} N P s$ homogeneously dispersed in an amorphous hydrogenated carbon matrix (SEM image in Table 1, [117]). As seen in the top of Fig. 10, they were able to control the chemical synthesis of the NPs inside the reactor on Tabinjector and the characteristics of the deposition were controlled by the low-pressure plasma reactor. During this work, studies to investigate the pulsed injection impact on the plasma were carried out.

As for the most recent reports, our group [134] attempted for the first time the pulsed injection of the colloidal solution (laboratory-made) [135] [136] in much lower-pressure plasma system such as $3 \mathrm{mTorr}$. The objective of this study was to elaborate $\mathrm{TiO}_{2}-\mathrm{SiO} \mathrm{NC}$ thin films though a versatile and agile hybrid process. The interest of very low pressure in terms of plasma species lies in the possibility to finely control the growth of the silica matrix which exhibits a high optical quality. To achieve the NCs synthesis, in a low-pressure PECVD system, a Kemstream liquid doser was mounted as shown in the experimental setup provided in Fig. 11a, b. The injection sequence was optimized to allow the solvent to be fully oxidized and the pressure to be maintained in a low range. Each sequence lasted one minute during which $\mathrm{N}$ pulses of $1 \mathrm{~ms}$ injection separated by $2 \mathrm{~s}$ OFF time were performed, with $N=0,2,10,30$. This sequence was repeated for a controlled duration. The cross section of the film (see Table 1, [119]) revealed a fairly homogeneous distribution of the NPs inside the matrix, at the local scale. Among others, the most prominent and promising result from this work was the fact that adjusting the parameters of the injection sequence (from $N=2$ to $N=30$ ), NC films with lower and higher $\mathrm{TiO}_{2} \mathrm{NPs}$ content (7-53\%) and thus different optical properties (refractive index 1.50-1.74) could be achieved. 


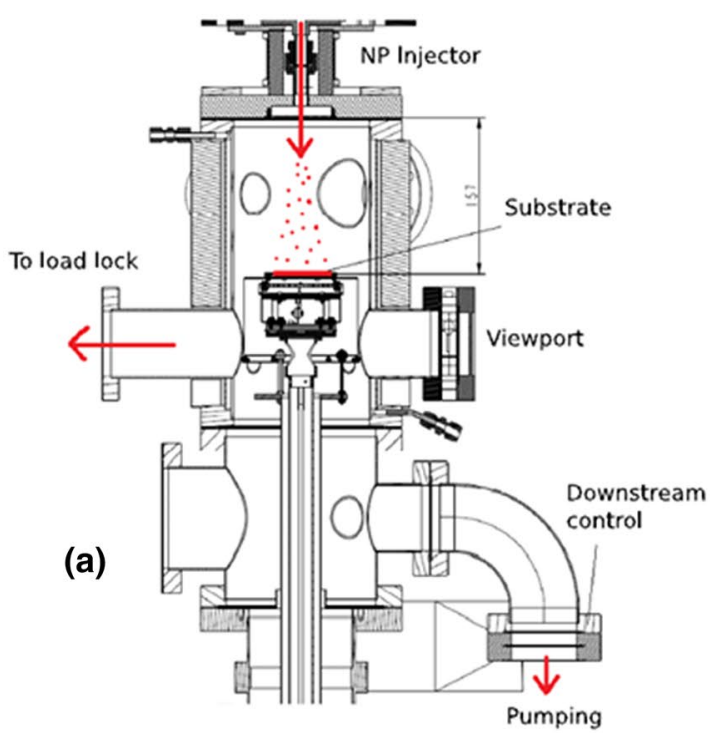

(b)

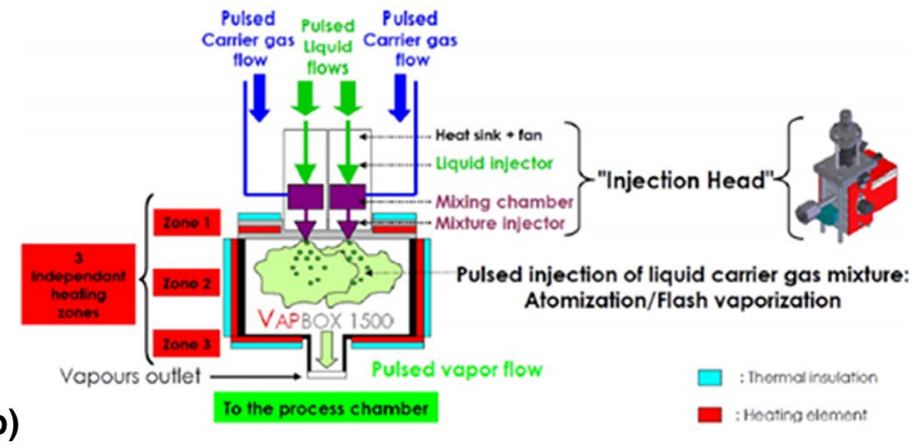

Fig. 7 a Schematic of the process chamber. b Schematic of the Kemstream Vapbox 1500 injection head. Reproduced with permission from [120], copyright 2016 AIP Publishing

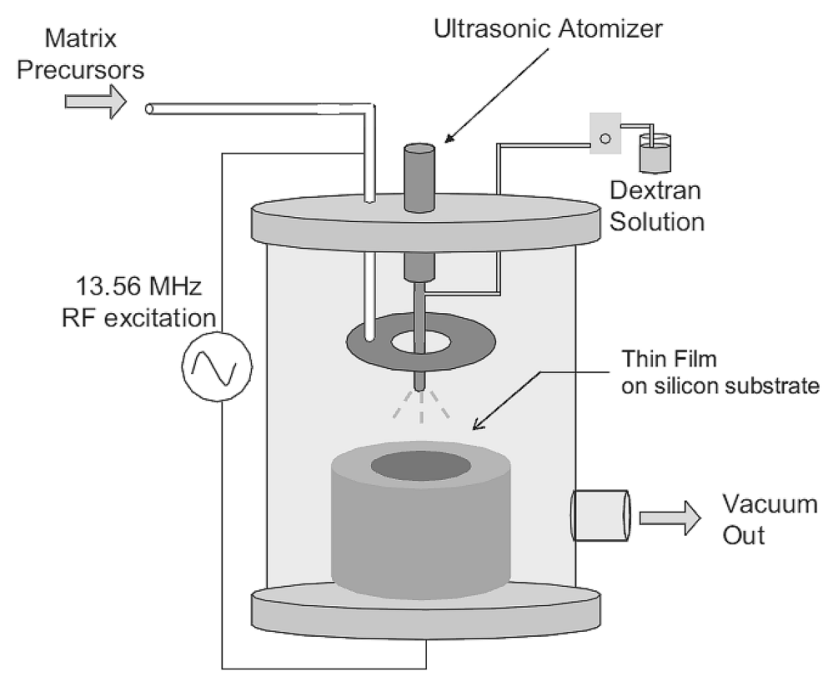

Fig. 8 Reactor configuration for simultaneous plasma-enhanced deposition of matrix material and ultrasonic atomization deposition of particles. Reproduced with permission from [126], copyright 2006 John Wiley and Sons Publishing

\subsubsection{Characteristics of the produced nanomaterials through the hybrid approaches}

Due to the originality of this hybrid approach coupling the gas and liquid phase processes, Table 1 is produced, indicating a majority of the works since 2006. In this table, details regarding the process parameters, the system used, the precursors and working pressure are given. Moreover, the characteristics of the produced films and the evolution of the NPs size upon deposition are discussed.
A first observation from this table is that the majority of the provided works were conducted at atmospheric pressure. This could be linked to the relative easier setup as there is no turbomolecular pump and the injection of the aerosol is facilitated by the geometry of the system and the gas flow configuration. The preponderant use of DBD configurations over plasma jets could be linked to the lower temperature the first exhibits, and the possibility to deposit over higher surface area. Additionally, DBD have the unique and main advantage of being cold plasmas (namely out of local thermodynamic equilibrium) created at atmospheric pressure, in other words, a lot of similarities with low-pressure plasmas but without huge pumping device. It remains nevertheless one difference between low-pressure plasmas and DBD, due to high pressure which is the low ion energy and very small mean free paths which limit the possibility of depositing dense films and can limit the homogeneity (in terms of thickness and composition, independently of the NC dispersion). On the other hand, it is suited for deposition on planar substrates but not on other geometries. An issue occurring frequently in these works is the agglomeration of the initial NPs upon deposition. Some more recent works, such as from Profili et al. [113], investigated the impact of the AC voltage parameters of the DBD power supply on the deposited size distribution of the NPs. In addition to this, regarding the low-pressure system Vervaele et al. [120] showed that for a low-pressure CVD system, the mass flow rate of the introduced solvent significantly affects the size of the deposited NPs. Furthermore, three general categories of experimental strategies were identified for the production of nanomaterials. First, the NPs colloidal solution was injected 
Fig. 9 A schematic diagram of the experimental apparatus used in [127-129]. Reproduced from [129], Open Access IOP Publishing

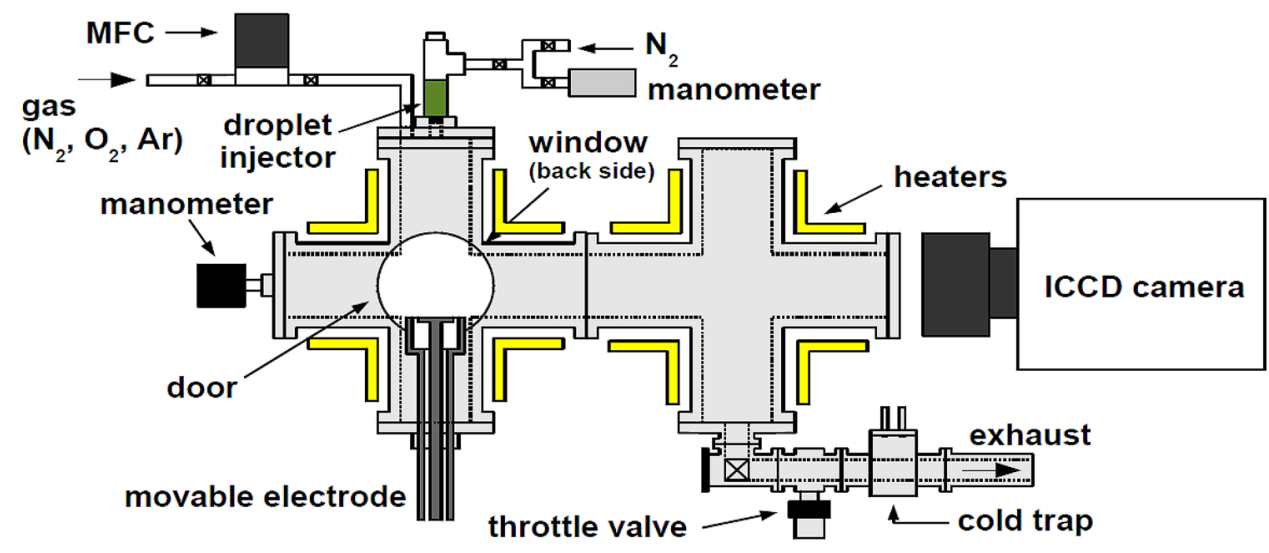

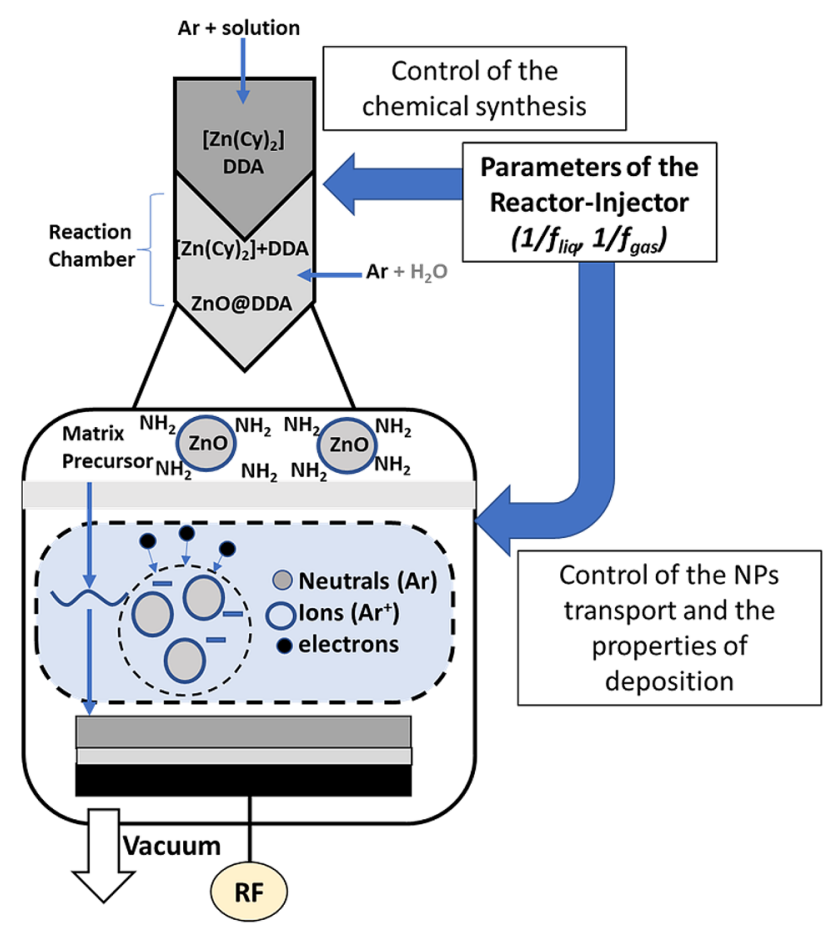

Fig. 10 Reactor-injector and RF low-pressure plasma system used by Carnide et al. Adapted with permission from [132]

only in the plasma system for the deposition of NPs. In this scenario, when the solvent is organic, a carbon-like matrix could be observed surrounding the NPs. Second, for the creation of NC thin films, the NPs were dissolved in the liquid precursor of the matrix. Third, the deposition of the matrix precursor and the NPs took place from two separate sources. Three works were identified with the latter experimental strategy. The first by Profili et al. [110] where two steps were followed, namely the deposition of the $\mathrm{TiO}_{2} \mathrm{NPs}$ (from the aerosol) and after the injection of the HMDSO vapor precursor in the DBD reactor. The created film was a layered nanocomposite. The second work was from Ross et Gleason [126] where the colloidal solution with the NPs was injected simultaneously with the HMDSO vapor precursor in the low-pressure (100-500 mTorr) plasma reactor (RF CCP). The third work was from our group [134] where the $\mathrm{TiO}_{2} \mathrm{NP}$ colloidal solution was introduced simultaneously with the HMDSO vapor precursor of the matrix in the low-pressure $3 \mathrm{mTorr}_{2}$ plasma reactor (RF ICP).

From the characteristics regarding the produced nanomaterials in Table 1, it appears that the majority of the works have an organic matrix. This could be linked with the transient effects happening during the liquid vaporization (pressure variation, discharge perturbation, etc.) or the released organic species that can affect the inorganic quality of the deposited matrix (in case it is preferred for the application of the produced films). Finally, the concentration of the distributed NPs has propelled the curiosity of the researchers. For the majority of the works the NPs content remains in low levels (less than 5\%). Brunet et al. [114] attempted to control the coverage percentage through the power supply frequency of the DBD (adjusting the process), whereas Fanelli et al. [109] chose to increase the NPs concentration in the solution (by adjusting the precursor). Finally, we [134] showed that it was possible through a specific approach and particularly by optimizing the sequence of injection to tune the $\mathrm{TiO}_{2} \mathrm{NPs}$ content up to $58 \%$ while achieving tunable optical properties of the film.

\section{Conclusion}

The aim of this review paper was to gather novel approaches for the deposition of NC thin films, based on the coupling of liquid- and gas-phase deposition processes. While oxide-based NC thin films (such as $\mathrm{TiO}_{2}-\mathrm{SiO}_{2} \mathrm{NCs}$ ) have several attractive applications, most of the works discussed in this review also include an organic matrix. This is linked to the novel character of these approaches and the complex phenomena induced when liquid and more specifically an organic solvent is 

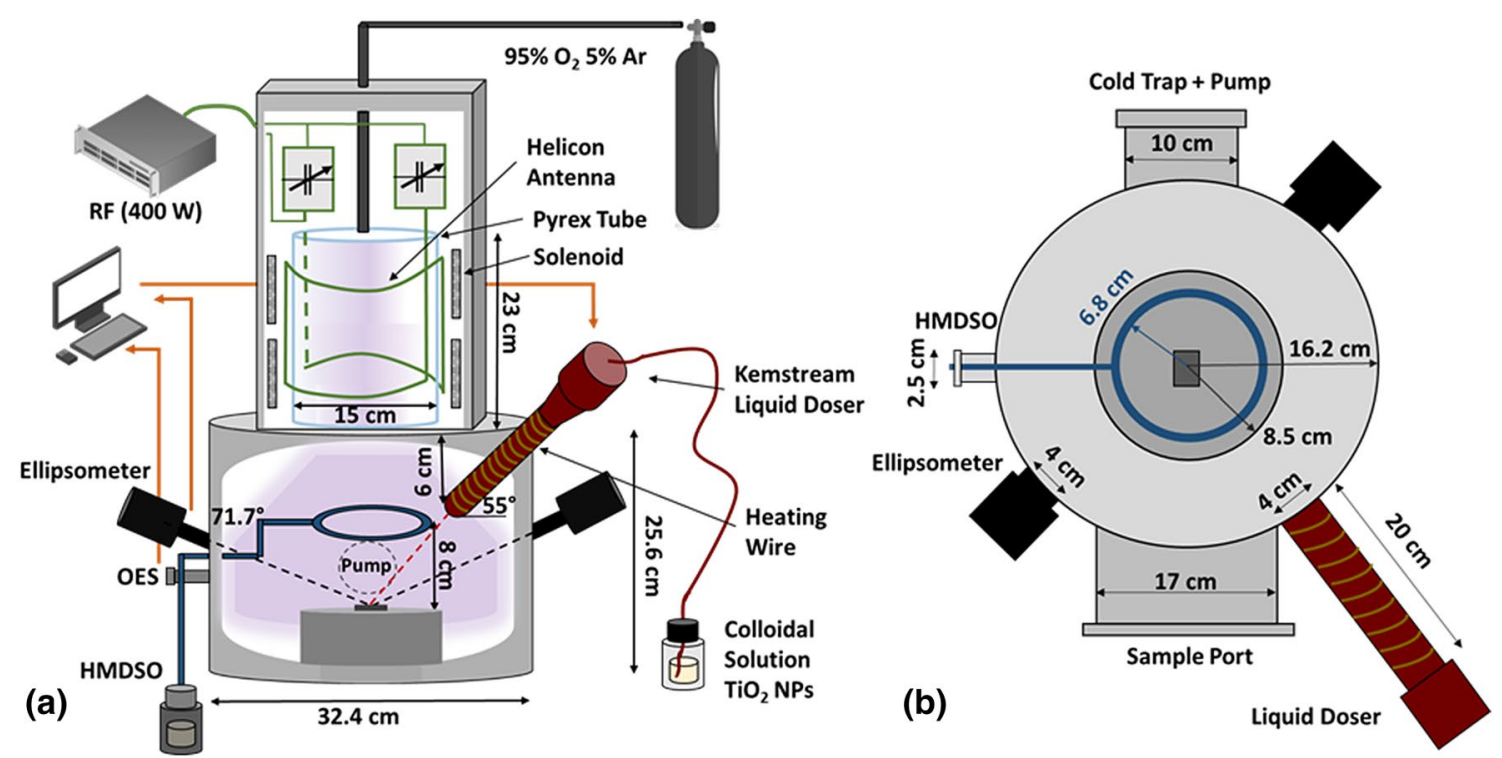

Fig. 11 Schematic of the hybrid experimental setup including the low-pressure ICP $\mathrm{O}_{2}$ reactor, the liquid doser apparatus (with red) and the HMDSO vapor distribution system (with bleu) at a side

introduced in gas-phase deposition systems. From this detailed comparative overview, the challenges and difficulties to develop NC films, retaining the initial monodispersity in size of the NPs, with controlled composition and homogeneous NPs dispersion in the matrix through plasma-based hybrid processes are clearly highlighted. Additionally, it is evidenced that approaches like these lack in computational and theoretical studies, which can be proven crucial for the optimization of the reported experimental setups. Finally, the paramount objective of these approaches is the ability to create an agile process, through which it can be possible to tune and adjust the properties of the NC film, with a high degree of freedom.

Acknowledgements The authors would like to thank Professor Luc Stafford and Dr. Jacopo Profili for their discussions regarding atmospheric pressure DBD hybrid systems.

\section{Declarations}

Conflict of interest On behalf of all authors, the corresponding author states that there is no conflict of interest.

Open Access This article is licensed under a Creative Commons Attribution 4.0 International License, which permits use, sharing, adaptation, distribution and reproduction in any medium or format, as long as you give appropriate credit to the original author(s) and the source, provide a link to the Creative Commons licence, and indicate if changes were made. The images or other third party material in this article are included in the article's Creative Commons licence, unless indicated otherwise in a credit line to the material. If material is not included in the article's Creative Commons licence and your intended use is not permitted by statutory regulation or exceeds the permitted view and $\mathbf{b}$ top view. The in situ characterization techniques are also indicated on this schematic. Reproduced from [134], copyright 2021 IOP Publishing

use, you will need to obtain permission directly from the copyright holder. To view a copy of this licence, visit http://creativecommons. org/licenses/by/4.0/.

\section{References}

1. Nelson JK (ed) (2010) Dielectric polymer nanocomposites. Springer, New York. ISBN 978-1-4419-1590-0. https://doi.org/ 10.1007/978-1-4419-1591-7

2. Pokropivny VV, Skorokhod VV (2007) Classification of nanostructures by dimensionality and concept of surface forms engineering in nanomaterial science. Mater Sci Eng C 27:990993. https://doi.org/10.1016/j.msec.2006.09.023

3. Jeevanandam J, Barhoum A, Chan YS, Dufresne A, Danquah MK (2018) Review on nanoparticles and nanostructured materials: history, sources, toxicity and regulations. Beilstein J Nanotechnol 9:1050-1074. https://doi.org/10.3762/bjnano.9.98

4. Sanchez C, Julián B, Belleville P, Popall M (2005) Applications of hybrid organic-inorganic nanocomposites. J Mater Chem 15:3559. https://doi.org/10.1039/b509097k

5. Zhang X-Y, Li H-P, Cui X-L, Lin Y (2010) Graphene/TiO 2 nanocomposites: synthesis, characterization and application in hydrogen evolution from water photocatalytic splitting. J Mater Chem 20:2801. https://doi.org/10.1039/b917240h

6. Rhim J-W, Park H-M, Ha C-S (2013) Bio-nanocomposites for food packaging applications. Prog Bionanocompos Green Plast Biomed Appl 38:1629-1652. https://doi.org/10.1016/j.progp olymsci.2013.05.008

7. Dong $H$, Wu Z, Lu F, Gao Y, El-Shafei A, Jiao B, Ning S, Hou X (2014) Optics-electrics highways: plasmonic silver nanowires@ $\mathrm{TiO}_{2}$ core-shell nanocomposites for enhanced dye-sensitized solar cells performance. Nano Energy 10:181-191. https://doi. org/10.1016/j.nanoen.2014.09.011

\section{SN Applied Sciences}


8. Xu J, Wang Y, Hu S (2017) Nanocomposites of graphene and graphene oxides: synthesis, molecular functionalization and application in electrochemical sensors and biosensors. A Review. Microchim Acta 184:1-44. https://doi.org/10.1007/ s00604-016-2007-0

9. Müller K, Bugnicourt E, Latorre $M$, Jorda M, Echegoyen Sanz Y, Lagaron J, Miesbauer O, Bianchin A, Hankin S, Bölz U et al (2017) Review on the processing and properties of polymer nanocomposites and nanocoatings and their applications in the packaging, automotive and solar energy fields. Nanomaterials 7:74. https://doi.org/10.3390/nano7040074

10. Rao Y, Chen S (2008) Molecular composites comprising $\mathrm{TiO}_{2}$ and their optical properties. Macromolecules 41:4838-4844. https://doi.org/10.1021/ma800371v

11. Belka R (2013) Analysis of optical properties of fullerenepalladium nanostructures using effective medium theory. In: Romaniuk RS (ed) Photonics applications in astronomy, communications, industry, and high-energy physics experiments 2013. Wilga, Poland, p 89030B. https://doi.org/10.1117/12. 2032015

12. Garahan A, Pilon L, Yin J, Saxena I (2007) Effective optical properties of absorbing nanoporous and nanocomposite thin films. J Appl Phys 101:014320. https://doi.org/10.1063/1.2402327

13. Lozovski V, Strilchuk G (2015) Optical properties of nanocomposite films with inclusions of the same dimensions as the film thickness. In: Proceedings of the 2015 IEEE 35th international conference on electronics and nanotechnology (ELNANO). IEEE, Kyiv, Ukraine, pp 158-160. https://doi.org/10.1109/ ELNANO.2015.7146860

14. Khan I, Saeed K, Khan I (2017) Nanoparticles: properties, applications and toxicities. Arab J Chem 12:908-931. https://doi.org/ 10.1016/j.arabjc.2017.05.011

15. Sarkar DK, Brassard D, Khakani MAE, Ouellet L (2007) Dielectric properties of sol-gel derived high-k titanium silicate thin films. Thin Solid Films 515:4788-4793. https://doi.org/10.1016/j.tsf. 2006.11.155

16. Brassard D, Sarkar DK, El Khakani MA, Ouellet L (2006) Compositional effect on the dielectric properties of high-k titanium silicate thin films deposited by means of a cosputtering process. J Vac Sci Technol Vac Surf Films 24:600-605. https://doi. org/10.1116/1.2180267

17. Li D, Carette M, Granier A, Landesman JP, Goullet A (2015) Effect of ion bombardment on the structural and optical properties of $\mathrm{TiO}_{2}$ thin films deposited from oxygen/titanium tetraisopropoxide inductively coupled plasma. Thin Solid Films 589:783791. https://doi.org/10.1016/j.tsf.2015.07.015

18. Li D, Bulou S, Gautier N, Elisabeth S, Goullet A, Richard-Plouet $M$, Choquet $P$, Granier A (2019) Nanostructure and photocatalytic properties of $\mathrm{TiO}_{2}$ films deposited at low temperature by pulsed PECVD. Appl Surf Sci 466:63-69. https://doi.org/10. 1016/j.apsusc.2018.09.230

19. Jolivet J-P, Cassaignon $S$, Chanéac $C$, Chiche D, Durupthy $O$, Portehault D (2010) Design of metal oxide nanoparticles: control of size, shape, crystalline structure and functionalization by aqueous chemistry. Comptes Rendus Chim 13:40-51. https:// doi.org/10.1016/j.crci.2009.09.012

20. Auffan $M$, Pedeutour $M$, Rose J, Masion A, Ziarelli F, Borschneck D, Chaneac C, Botta C, Chaurand P, Labille J et al (2010) Structural degradation at the surface of a $\mathrm{TiO}_{2}$-based nanomaterial used in cosmetics. Environ Sci Technol 44:2689-2694. https:// doi.org/10.1021/es903757q

21. Jamuna-Thevi K, Bakar SA, Ibrahim S, Shahab N, Toff MRM (2011) Quantification of silver ion release, in vitro cytotoxicity and antibacterial properties of nanostuctured Ag doped $\mathrm{TiO}_{2}$ coatings on stainless steel deposited by RF magnetron sputtering. Vacuum 86:235-241. https://doi.org/10.1016/j. vacuum.2011.06.011

22. Homola $T$, Shekargoftar $M$, Dzik $P$, Krumpolec $R$, Ďurašová $Z$, Veselý $M$, Černák $M(2017)$ Low-temperature $\left(70^{\circ} \mathrm{C}\right)$ ambient air plasma-fabrication of inkjet-printed mesoporous $\mathrm{TiO}_{2}$ flexible photoanodes. Flex Print Electron 2:035010. https://doi.org/10. 1088/2058-8585/aa88e6

23. O'Regan B, Grätzel M (1991) A low-cost, high-efficiency solar cell based on dye-sensitized colloidal $\mathrm{TiO}_{2}$ films. Nature 353:737-740. https://doi.org/10.1038/353737a0

24. Adak D, Ghosh S, Chakrabarty P, Mondal A, Saha H, Mukherjee $\mathrm{R}$, Bhattacharyya $\mathrm{R}$ (2017) Self-cleaning $\mathrm{V}-\mathrm{TiO}_{2}: \mathrm{SiO}_{2}$ thin-film coatings with enhanced transmission for solar glass cover and related applications. Sol Energy 155:410-418. https://doi.org/ 10.1016/j.solener.2017.06.014

25. Adak D, Ghosh S, Chakraborty P, Srivatsa KMK, Mondal A, Saha H, Mukherjee R, Bhattacharyya R (2018) Non lithographic block copolymer directed self-assembled and plasma treated selfcleaning transparent coating for photovoltaic modules and other solar energy devices. Sol Energy Mater Sol Cells 188:127139. https://doi.org/10.1016/j.solmat.2018.08.011

26. Guldin S, Kohn P, Stefik M, Song J, Divitini G, Ecarla F, Ducati C, Wiesner U, Steiner U (2013) Self-cleaning antireflective optical coatings. Nano Lett 13:5329-5335. https://doi.org/10.1021/ nl402832u

27. Bellanger H, Darmanin T, Taffin de Givenchy E, Guittard F (2014) Chemical and physical pathways for the preparation of superoleophobic surfaces and related wetting theories. Chem. Rev. 114:2694-2716. https://doi.org/10.1021/cr400169m

28. Du Y, Lv Y, Wang F, Li X, Li C (2010) Effect of $\mathrm{TiO}_{2}$ nanoparticles on the breakdown strength of transformer oil. In: Proceedings of the 2010 IEEE international symposium on electrical insulation. IEEE, San Diego, CA, USA, pp 1-3. https://doi.org/10.1109/ ELINSL.2010.5549772

29. Hoffmann MR, Martin ST, Choi W, Bahnemann DW (1995) Environmental applications of semiconductor photocatalysis. Chem Rev 95:69-96. https://doi.org/10.1021/cr00033a004

30. Gupta SM, Tripathi M (2011) A review of $\mathrm{TiO}_{2}$ nanoparticles. Chin Sci Bull 56:1639-1657. https://doi.org/10.1007/s11434-011-4476-1

31. Enright B, Fitzmaurice D (1996) Spectroscopic determination of electron and hole effective masses in a nanocrystalline semiconductor film. J Phys Chem 100:1027-1035. https://doi.org/ 10.1021/jp951142w

32. Pighini $\mathrm{C}$ (2006) Synthèses de nanocristaux de $\mathrm{TiO}_{2}$ anatase à distribution de taille contrôlée. Influence de la taille des cristallites sur le spectre Raman et étude des propriétés de surface. Bourgogne, France

33. Zhang LD, Zhang HF, Wang GZ, Mo CM, Zhang Y (1996) Dielectric behaviour of nano-TiO ${ }_{2}$ bulks. Phys Status Solidi A 157:483491. https://doi.org/10.1002/pssa.2211570232

34. Liu G, Jian W, Jin H, Shi Z, Qiao G (2011) A high dielectric constant in nano- $\mathrm{TiO}_{2}$ ceramic prepared by a rapid and high-pressure sintering process. Scr Mater 65:588-591. https://doi.org/ 10.1016/j.scriptamat.2011.06.031

35. Avinash BS, Chathurmukha VS, Naveen CS, Rajeeva MP, Jayanna HS, Ashok RL (2016) Influence of particle size on band gap and dielectric properties of $\mathrm{TiO}_{2}$ nanomaterials. Bikaner, India, $\mathrm{p}$ 020347. https://doi.org/10.1063/1.4946398

36. Davis JA (2018) Energy density limits of multiphase composites with dielectric nanoparticles. IEEE Trans Nanotechnol 17:250260. https://doi.org/10.1109/TNANO.2018.2790955

37. Dang Z-M, Yuan J-K, Yao S-H, Liao R-J (2013) Flexible nanodielectric materials with high permittivity for power energy storage. Adv Mater 25:6334-6365. https://doi.org/10.1002/adma. 201301752 
38. Sarkar DK, Brassard D, El Khakani MA, Ouellet L (2005) Singleelectron tunneling at room temperature in $\mathrm{TixSi} 1-\mathrm{xO} 2$ nanocomposite thin films. Appl Phys Lett 87:253108. https://doi.org/ 10.1063/1.2147729

39. Fanelli F, Fracassi F (2014) Aerosol-assisted atmospheric pressure cold plasma deposition of organic-inorganic nanocomposite coatings. Plasma Chem Plasma Process 34:473-487. https://doi.org/10.1007/s11090-013-9518-9

40. Ajayan PM, Schadler LS, Braun PV (2005) Nanocomposite science and technology; 2nd repr.; Wiley-VCH: Weinheim, ISBN 978-3-527-30359-5.

41. Kermadi S, Agoudjil N, Sali S, Boumaour M, Bourgeois S, Marco de Lucas MC (2014) Sol-gel synthesis of XTiO2(100-x)SiO2 nanocomposite thin films: structure, optical and antireflection properties. Thin Solid Films 564:170-178. https://doi.org/ 10.1016/j.tsf.2014.05.068

42. Kermadi S, Agoudjil N, Sali S, Zougar L, Boumaour M, Broch L, En Naciri A, Placido F (2015) Microstructure and optical dispersion characterization of nanocomposite sol-gel $\mathrm{TiO}_{2}-\mathrm{SiO}_{2}$ thin films with different compositions. Spectrochim Acta A Mol Biomol Spectrosc 145:145-154. https://doi.org/10.1016/j.saa. 2015.02.110

43. Lopes de Jesus MAM, de Magalhães Gomes GH, Ferlauto AS, Seara LM, de Mello FA (2019) Della santina mohallem, N. A systematic study of multifunctional XTiO2/(100-x)SiO2 thin films prepared by sol-gel process. J Sol-Gel Sci Technol 89:380-391. https://doi.org/10.1007/s10971-018-4867-8

44. Charitidis CA, Georgiou P, Koklioti MA, Trompeta A-F, Markakis V (2014) Manufacturing nanomaterials: from research to industry. Manuf Rev 1:11. https://doi.org/10.1051/mfreview/ 2014009

45. Hench LL, West JK (1990) The sol-gel process. Chem Rev 90:33-72. https://doi.org/10.1021/cr00099a003

46. Kwiatkowski K, Lukehart C (2000) Nanocomposites prepared by sol-gel methodsSynthesis and characterization. In: Handbook of nanostructured materials and nanotechnology, vol 1. Elsevier, pp 387-421. ISBN 978-0-12-513760-7. https:// doi.org/10.1016/B978-012513760-7/50011-3

47. Nikam AV, Prasad BLV, Kulkarni AA (2018) Wet chemical synthesis of metal oxide nanoparticles: a review. CrystEngComm 20:5091-5107. https://doi.org/10.1039/C8CE00487K

48. Guglielmi M, Kickelbick G, Martucci A (2014) Sol-gel nanocomposites. Springer, New York, NY. ISBN 978-1-4939-12087. https://doi.org/10.1007/978-1-4939-1209-4

49. Ebelmen Sur I'hyalite artificielle et I'hydrophane. Comptes Rendus Hebd. Séances Académie Sci.1847, 25, 854-856

50. Dong W, Lee CW, Lu X, Sun Y, Hua W, Zhuang G, Zhang S, Chen J, Hou H, Zhao D (2010) Synchronous role of coupled adsorption and photocatalytic oxidation on ordered mesoporous anatase $\mathrm{TiO}_{2}-\mathrm{SiO}_{2}$ nanocomposites generating excellent degradation activity of RhB dye. Appl Catal B Environ 95:197207. https://doi.org/10.1016/j.apcatb.2009.12.025

51. Nilchi A, Janitabar-Darzi S, Mahjoub AR, Rasouli-Garmarodi S (2010) New $\mathrm{TiO}_{2} / \mathrm{SiO}_{2}$ nanocomposites-phase transformations and photocatalytic studies. Colloids Surf Physicochem Eng Asp 361:25-30. https://doi.org/10.1016/j.colsurfa.2010. 03.006

52. Nilchi A, Janitabar-Darzi S, Rasouli-Garmarodi S (2011) Sol-Gel Preparation of nanoscale $\mathrm{TiO}<\mathrm{Sub}>2</ \mathrm{Sub}>/ \mathrm{SiO}<\mathrm{Sub}>2<1$ Sub $>$ composite for eliminating of Con Red Azo Dye. Mater Sci Appl 02:476-480. https://doi.org/10.4236/msa.2011. 25064

53. Dong W, Sun Y, Ma Q, Zhu L, Hua W, Lu X, Zhuang G, Zhang S, Guo Z, Zhao D (2012) Excellent photocatalytic degradation activities of ordered mesoporous anatase $\mathrm{TiO}_{2}-\mathrm{SiO}_{2}$ nanocomposites to various organic contaminants. J Hazard Mater
229-230:307-320. https://doi.org/10.1016/j.jhazmat.2012.06. 002

54. Pinho L, Mosquera MJ (2013) Photocatalytic activity of $\mathrm{TiO}_{2}-$ $\mathrm{SiO}_{2}$ nanocomposites applied to buildings: influence of particle size and loading. Appl Catal B Environ 134-135:205-221. https://doi.org/10.1016/j.apcatb.2013.01.021

55. Mao Q, Zeng D, Xu K, Xie C (2014) Fabrication of porous $\mathrm{TiO}_{2}-$ $\mathrm{SiO}_{2}$ multifunctional anti-reflection coatings by sol-gel spin coating method. RSC Adv 4:58101-58107. https://doi.org/10. 1039/C4RA10424B

56. Holtzinger $C$, Rapenne $L$, Chaudouët $P$, Berthomé $G$, Joud JC, Langlet M (2012) Influence of sol composition on natural superhydrophilicity of sol gel-derived $\mathrm{TiO}_{2}-\mathrm{SiO}_{2}$ nanocomposite thin films. Emerg Mater Res 1:127-135. https://doi.org/10. 1680/emr.11.00024

57. Pakdel E, Daoud WA, Wang X (2013) Self-cleaning and superhydrophilic wool by $\mathrm{TiO}_{2} / \mathrm{SiO}_{2}$ nanocomposite. Appl Surf Sci 275:397-402. https://doi.org/10.1016/j.apsusc.2012.10.141

58. de Chiara MLV, Pal S, Licciulli A, Amodio ML, Colelli G (2015) Photocatalytic degradation of ethylene on mesoporous $\mathrm{TiO}_{2} /$ $\mathrm{SiO}_{2}$ nanocomposites: effects on the ripening of mature green tomatoes. Biosyst Eng 132:61-70. https://doi.org/10.1016/j. biosystemseng.2015.02.008

59. Kudryavtsev PG, Figovsky OL (2016) Nanocomposites based on hybrid organo-silicate matrix. Part 2. Nanotehnologii v Stroitel'stve 8(2):20-44. https://doi.org/10.15828/ 2075-8545-2016-8-2-20-44

60. Kondratiev V (2017) Processing and characterization of transparent electrode materials. https://doi.org/10.13140/RG.2.2. 34906.24008

61. Chen C, Bai H, Chein H, Chen TM (2007) Continuous generation of $\mathrm{TiO}_{2}$ nanoparticles by an atmospheric pressure plasma-enhanced process. Aerosol Sci Technol 41:10181028. https://doi.org/10.1080/02786820701694355

62. Chen C, Bai H, Chang C (2007) Effect of plasma processing gas composition on the nitrogen-doping status and visible light photocatalysis of $\mathrm{TiO}_{2}$. J Phys Chem C 111:15228-15235. https://doi.org/10.1021/jp0716233

63. Liu W-J, Lai Y-L (2009) Investigation of novel low temperature atmospheric pressure plasma system for deposition photo-catalytic $\mathrm{TiO}_{2}$ thin film. Surf Modif Mater Ion Beams 2011(206):959-962. https://doi.org/10.1016/j.surfcoat.2011. 03.103

64. Klenko Y, Pichal J (2012) TiOx films deposited by plasma enhanced chemical vapour deposition method in atmospheric dielectric barrier discharge plasma. Plasma Chem Plasma Process 32:1215-1225. https://doi.org/10.1007/ s11090-012-9401-0

65. Shirafuji T, Miyazaki Y, Hayashi Y, Nishino S (1999) PE-CVD of fluorocarbon/SiO composite thin films using C4F8 and HMDSO. Plasmas Polym 4:57-75. https://doi.org/10.1023/A: 1021803615715

66. Choukourov A, Pihosh Y, Stelmashuk V, Biederman $H$, Slavinská D, Kormunda M, Zajičková L (2002) Rf sputtering of composite SiOx/plasma polymer films and their basic properties. Proc Symp C Prtoect Coat Thin Films 151-152:214-217. https://doi.org/10.1016/S0257-8972(01)01622-X

67. Granier A, Borvon G, Bousquet A, Goullet A, Leteinturier C, van der Lee $A$ (2006) Mechanisms involved in the conversion of PpHMDSO Films into SiO2-like by oxygen plasma treatment. Plasma Process Polym 3:365-373. https://doi.org/10.1002/ ppap. 200600022

68. Drabik M, Kousal J, Pihosh $\mathrm{Y}$, Choukourov A, Biederman $\mathrm{H}$, Slavinska D, Mackova A, Boldyreva A, Pesicka J (2007) Composite $\mathrm{SiOx} /$ hydrocarbon plasma polymer films prepared by RF 
magnetron sputtering of $\mathrm{SiO}_{2}$ and polyimide. Vacuum 81:920927. https://doi.org/10.1016/j.vacuum.2006.10.013

69. Bousquet A, Goullet A, Leteinturier C, Coulon N, Granier A (2008) Influence of ion bombardment on structural and electrical properties of $\mathrm{SiO}_{2}$ thin films deposited from $\mathrm{O}_{2} / \mathrm{HMDSO}$ inductively coupled plasmas under continuous wave and pulsed modes. Eur Phys J Appl Phys 42:3-8. https://doi.org/ 10.1051/epjap:2008038

70. Hu E-T, Liu X-X, Cai Q-Y, Yao Y, Zang K-Y, Yu K-H, Wei W, Xu X-X, Zheng Y-X, Wang S-Y et al (2017) Tunable optical properties of co-sputtered Ti-SiO_2 nanocomposite thin films. Opt Mater Express 7:2387. https://doi.org/10.1364/OME.7.002387

71. Chen J-S, Chao S, Kao J-S, Niu H, Chen C-H (1996) Mixed films of TiO_2-SiO_2 deposited by double electron-beam coevaporation. Appl Opt 35:90. https://doi.org/10.1364/AO.35.000090

72. Ghodselahi T, Vesaghi MA, Shafiekhani A, Baradaran A, Karimi A, Mobini Z (2008) Co-deposition process of RF-sputtering and RF-PECVD of copper/carbon nanocomposite films. Surf Coat Technol 202:2731-2736. https://doi.org/10.1016/j.surfcoat. 2007.10.009

73. El Mel AA, Angleraud B, Gautron E, Granier A, Tessier PY (2010) Microstructure and composition of TiC/a-C: $\mathrm{H}$ nanocomposite thin films deposited by a hybrid IPVD/PECVD process. Surf Coat Technol 204:1880-1883. https://doi.org/10.1016/j.surfc oat.2009.09.045

74. Kolipaka KL, Brueser V, Schlueter R, Quade A, Schaefer J, Wulff H, Strunskus T, Faupel F (2012) Simple method of hybrid PVD/ PECVD to prepare well-dispersed cobalt-plasma polymerized hexamethyldisilazane nanocomposites. Surf Coat Technol 207:565-570. https://doi.org/10.1016/j.surfcoat.2012.07.073

75. Bedel L, Cayron C, Jouve M, Maury F (2012) Embedded layer of Ag nanoparticles prepared by a combined PECVD/PVD process producing $\mathrm{SiO}_{x} \mathrm{C}_{y}-\mathrm{Ag}$ nanocomposite thin films. Nanotechnology 23:015603. https://doi.org/10.1088/0957-4484/23/1/ 015603

76. Kylián $O$, Štefaníková R, Kuzminova A, Hanuš J, Solař $P$, Kúš $P$, Cieslar M, Biederman H (2020) In-flight plasma modification of nanoparticles produced by means of gas aggregation sources as an effective route for the synthesis of core-satellite Ag/ plasma polymer nanoparticles. Plasma Phys Control Fusion 62:014005. https://doi.org/10.1088/1361-6587/ab4115

77. Biederman H, Kylian O, Drabik M, Choukourov A, Polonskyi O, Solar P (2012) Nanocomposite and nanostructured films with plasma polymer matrix. Surf Coat Technol 211:127-137. https://doi.org/10.1016/j.surfcoat.2011.09.011

78. Biederman H (2011) Nanocomposites and nanostructures based on plasma polymers. Surf Coat Technol 205:S10-S14. https://doi.org/10.1016/j.surfcoat.2011.03.115

79. Patelli N, Migliori A, Morandi V, Pasquini L (2019) One-step synthesis of metal/oxide nanocomposites by gas phase condensation. Nanomaterials 9:219. https://doi.org/10.3390/nano9 020219

80. Nikitin D, Hanuš J, Ali-Ogly S, Polonskyi O, Drewes J, Faupel F, Biederman H, Choukourov A (2019) The evolution of Ag nanoparticles inside a gas aggregation cluster source. Plasma Process Polym 16:1900079. https://doi.org/10.1002/ppap.20190 0079

81. Košutová T, Horák L, Shelemin $A$, Vaidulych $M$, Hanuš J, Biederman H, Kylián O, Solař P, Cieslar M, Choukourov A et al (2020) Synthesis and microstructure investigation of heterogeneous metal-plasma polymer Ag/HMDSO nanoparticles. Surf Interface Anal. https://doi.org/10.1002/sia.6779

82. Solař $P$, Hanuš J, Cieslar M, Košutová T, Škorvánková K, Kylián O, Kúš P, Biederman H (2020) Composite Ni@Ti nanoparticles produced in arrow-shaped gas aggregation source. J Phys Appl Phys 53:195303. https://doi.org/10.1088/1361-6463/ab7353
83. Balasubramanian B, Kraemer KL, Reding NA, Skomski R, Ducharme S, Sellmyer DJ (2010) Synthesis of monodisperse $\mathrm{TiO}_{2}$-paraffin core-shell nanoparticles for improved dielectric properties. ACS Nano 4:1893-1900. https://doi.org/10.1021/nn901 6422

84. Drabik M, Choukourov A, Artemenko A, Polonskyi O, Kylian O, Kousal J, Nichtova L, Cimrova V, Slavinska D, Biederman H (2011) Structure and composition of titanium nanocluster films prepared by a gas aggregation cluster source. J Phys Chem C 115:20937-20944. https://doi.org/10.1021/jp2059485

85. Martínez L, Mayoral A, Espiñeira M, Roman E, Palomares FJ, Huttel Y (2017) Core@shell, Au@TiOx nanoparticles by gas phase synthesis. Nanoscale 9:6463-6470. https://doi.org/10.1039/ C7NR01148B

86. Kousal J, Kolpaková A, Shelemin A, Kudrna P, Tichý M, Kylián O, Hanuš J, Choukourov A, Biederman H (2017) Monitoring of conditions inside gas aggregation cluster source during production of Ti/TiOx nanoparticles. Plasma Sources Sci Technol 26:105003. https://doi.org/10.1088/1361-6595/aa88e8

87. Huttel Y (ed) (2017) Gas-phase synthesis of nanoparticles. Wiley-VCH, Weinheim, Germany. ISBN 978-3-527-34060-6

88. Kratochvíl J, Kuzminova A, Kylián O (2018) State-of-the-art, and perspectives of Silver/Plasma Polymer Antibacterial Nanocomposites. Antibiotics 7:78. https://doi.org/10.3390/antibiotic s7030078

89. Nandiyanto ABD, Okuyama K (2011) Progress in developing spray-drying methods for the production of controlled morphology particles: from the nanometer to submicrometer size ranges. Adv Powder Technol 22:1-19. https://doi.org/ 10.1016/j.apt.2010.09.011

90. Suhendi A, Nandiyanto ABD, Munir MM, Ogi T, Gradon L, Okuyama K (2013) Self-assembly of colloidal nanoparticles inside charged droplets during spray-drying in the fabrication of nanostructured particles. Langmuir 29:13152-13161. https://doi.org/10.1021/la403127e

91. Wang $X$, Masumoto $H$, Someno $Y$, Hirai T (1999) Microstructure and optical properties of amorphous $\mathrm{TiO}_{2}-\mathrm{SiO}_{2}$ composite ${ }^{\oplus} \mathrm{ms}$ synthesized by helicon plasma sputtering. Thin Solid Films 338:105-109

92. Wang W-N, Itoh Y, Lenggoro IW, Okuyama K (2004) Nickel and nickel oxide nanoparticles prepared from nickel nitrate hexahydrate by a low pressure spray pyrolysis. Mater Sci Eng B 111:69-76. https://doi.org/10.1016/j.mseb.2004.03.024

93. Wang W-N, Purwanto A, Lenggoro IW, Okuyama K, Chang H, Jang HD (2008) Investigation on the correlations between droplet and particle size distribution in ultrasonic spray pyrolysis. Ind Eng Chem Res 47:1650-1659. https://doi.org/ 10.1021/ie070821d

94. Schaldach G, Berger L, Razilov I, Berndt H (2002) characterization of a cyclone spray chamber for ICP spectrometry by computer simulation. J Anal At Spectrom 17:334-344. https://doi.org/10.1039/b106024b

95. Westphal CS, Kahen K, Rutkowski WF, Acon BW, Montaser A (2004) Demountable direct injection high efficiency nebulizer for inductively coupled plasma mass spectrometry. Spectrochim Acta Part B At Spectrosc 59:353-368. https:// doi.org/10.1016/j.sab.2004.01.004

96. Matusiewicz H, Ślachciński M (2017) Simultaneous determination of $\mathrm{As}, \mathrm{Bi}, \mathrm{Sb}$, Se and $\mathrm{Sn}$ by microwave induced plasma spectrometry using a quadruple-mode microflow ultrasonic nebulizer for in situ hydride generation with internal standardization. Microchem J 131:70-78. https://doi.org/10.1016/j. microc.2016.11.017

97. Giersz J, Bartosiak M, Jankowski K (2017) Sensitive determination of $\mathrm{Hg}$ together with $\mathrm{Mn}, \mathrm{Fe}, \mathrm{Cu}$ by combined photochemical vapor generation and pneumatic nebulization in 
the programmable temperature spray chamber and inductively coupled plasma optical emission spectrometry. Talanta 167:279-285. https://doi.org/10.1016/j.talanta.2017.02.018

98. Matusiewicz H, Ślachciński M (2017) Analytical evaluation of a quadruple-mode micro-flow ultrasonic nebulizer for sample introduction in microwave induced plasma spectrometry. Microchem J 130:345-352. https://doi.org/10.1016/j.microc. 2016.10.010

99. Brinley E, Babu KS, Seal S (2007) The solution precursor plasma spray processing of nanomaterials. JOM 59:54-59. https://doi.org/10.1007/s11837-007-0090-8

100. Boscher ND, Choquet P, Duday D, Kerbellec N, Lambrechts J-C, Maurau R (2011) Luminescent lanthanide-based hybrid coatings deposited by atmospheric pressure plasma assisted chemical vapour deposition. J Mater Chem 21:18959. https:// doi.org/10.1039/c1jm14659a

101. Fauchais P, Joulia A, Goutier S, Chazelas C, Vardelle M, Vardelle A, Rossignol S (2013) Suspension and solution plasma spraying. J Phys Appl Phys 46:224015. https://doi.org/10. 1088/0022-3727/46/22/224015

102. Haapanen J, Aromaa M, Teisala $H$, Tuominen M, Stepien M, Saarinen JJ, Heikkilä M, Toivakka M, Kuusipalo J, Mäkelä JM (2015) Binary TiO2/SiO2 nanoparticle coating for controlling the wetting properties of paperboard. Mater Chem Phys 149150:230-237. https://doi.org/10.1016/j.matchemphys.2014. 10.011

103. Dembele A, Rahman M, Reid I, Twomey B, MacElroy JMD, Dowling DP (2011) Deposition of hybrid organic-inorganic composite coatings using an atmospheric plasma jet system. J Nanosci Nanotechnol 11:8730-8737. https://doi.org/10.1166/jnn.2011. 3459

104. Schäfer J, Fricke K, Mika F, Pokorná Z, Zajíčková L, Foest R (2017) Liquid assisted plasma enhanced chemical vapour deposition with a non-thermal plasma jet at atmospheric pressure. Thin Solid Films 630:71-78. https://doi.org/10.1016/j.tsf.2016.09.022

105. Liguori A, Traldi E, Toccaceli E, Laurita R, Pollicino A, Focarete ML, Colombo V, Gherardi M (2016) Co-deposition of plasmapolymerized polyacrylic acid and silver nanoparticles for the production of nanocomposite coatings using a non-equilibrium atmospheric pressure plasma jet: co-deposition of plasma-polymerized polyacrylic acid and silver nanoparticles. Plasma Process Polym 13:623-632. https://doi.org/10.1002/ ppap. 201500143

106. Marino E, Huijser T, Creyghton $Y$, van der Heijden A (2007) Synthesis and coating of copper oxide nanoparticles using atmospheric pressure plasmas. Surf Coat Technol 201:9205-9208. https://doi.org/10.1016/j.surfcoat.2007.04.091

107. Bardon J, Bour J, Del Frari D, Arnoult C, Ruch D (2009) Dispersion of cerium-based nanoparticles in an organosilicon plasma polymerized coating: effect on corrosion protection. Plasma Process Polym 6:S655-S659. https://doi.org/10.1002/ppap. 200931710

108. Del Frari D, Bour J, Bardon J, Buchheit O, Arnoult C, Ruch D (2010) Hybrid layers deposited by an atmospheric pressure plasma process for corrosion protection of galvanized steel. J Nanosci Nanotechnol 10:2611-2619. https://doi.org/10.1166/ jnn.2010.1460

109. Fanelli F, Mastrangelo AM, Fracassi F (2014) Aerosol-assisted atmospheric cold plasma deposition and characterization of superhydrophobic organic-inorganic nanocomposite thin films. Langmuir 30:857-865. https://doi.org/10.1021/la404 $755 n$

110. Profili J, Levasseur O, Blaisot J-B, Koronai A, Stafford L, Gherardi N (2016) Nebulization of nanocolloidal suspensions for the growth of nanocomposite coatings in dielectric barrier discharges. Plasma Process Polym 13:981-989. https://doi.org/ 10.1002/ppap.201500223

111. Profili J, Levasseur O, Naudé N, Chaneac C, Stafford L, Gherardi $\mathrm{N}$ (2016) Influence of the voltage waveform during nanocomposite layer deposition by aerosol-assisted atmospheric pressure townsend discharge. J Appl Phys 120:053302. https://doi. org/10.1063/1.4959994

112. Profili J, Levasseur O, Koronai A, Stafford L, Gherardi N (2017) Deposition of nanocomposite coatings on wood using cold discharges at atmospheric pressure. Surf Coat Technol 309:729737. https://doi.org/10.1016/j.surfcoat.2016.10.095

113. Profili J, Dap S, Levasseur O, Naude N, Belinger A, Stafford L, Gherardi N (2017) Interaction of atomized colloid with an AC electric field in a dielectric barrier discharge reactor used for deposition of nanocomposite coatings. J Phys Appl Phys 50:075201. https://doi.org/10.1088/1361-6463/aa515f

114. Brunet $P$, Rincón R, Martinez J-M, Matouk Z, Fanelli F, Chaker M, Massines F (2017) Control of composite thin film made in an $\mathrm{Ar} /$ Isopropanol/ $/ \mathrm{TiO}_{2}$ nanoparticles dielectric barrier discharge by the excitation frequency. Plasma Process Polym. https://doi. org/10.1002/ppap.201700049

115. Brunet $P$ (2017) Procédé de dépôt de couches minces nanocomposites par décharge à barrière diélectrique: de l'aérosol d'une suspension colloïdale à la morphologie du dépôt. Perpignan, FRANCE

116. Model 3076 Constant Output Atomizer Instruction Manual. 63.

117. Bruggeman PJ, Kushner MJ, Locke BR, Gardeniers JGE, Graham WG, Graves DB, Hofman-Caris RCHM, Maric D, Reid JP, Ceriani E et al (2016) Plasma-liquid interactions: a review and roadmap. Plasma Sources Sci Technol 25:053002. https://doi.org/10.1088/ 0963-0252/25/5/053002

118. Hemmer E, Kumakiri I, Lecerf N, Bredesen R, Barth S, Altmayer J, Donia N, Cavelius C, Soga K, Mathur S (2012) Nanostructured $\mathrm{ZrO}_{2}$ membranes prepared by liquid-injection chemical vapor deposition. Microporous Mesoporous Mater 163:229-236. https://doi.org/10.1016/j.micromeso.2012.06.057

119. Avril L, Boudon J, Marco de Lucas MC, Imhoff L (2014) Alumina particle reinforced $\mathrm{TiO} 2$ composite films grown by direct liquid injection MOCVD. Vacuum 107:259-263. https://doi.org/ 10.1016/j.vacuum.2014.02.020

120. Vervaele $M$, De Roo B, Deschaume $O$, Rajala $M$, Guillon $H$, Sousa M, Bartic C, Van Haesendonck C, Seo JW, Locquet J-P (2016) Development of a new direct liquid injection system for nanoparticle deposition by chemical vapor deposition using nanoparticle solutions. Rev Sci Instrum 87:025101. https://doi.org/ 10.1063/1.4940937

121. Li Z, Gordon RG, Pallem V, Li H, Shenai DV (2010) Direct-liquidinjection chemical vapor deposition of nickel nitride films and their reduction to nickel films. Chem Mater 22:3060-3066. https://doi.org/10.1021/cm903636j

122. Vervaele $M$, De Roo B, Debehets J, Sousa M, Zhang L, Van Bilzen B, Seré S, Guillon H, Rajala M, Seo JW et al (2017) A novel direct liquid injection low pressure chemical vapor deposition system (DLI-LPCVD) for the deposition of thin films: a novel direct liquid injection low pressure chemical. Adv Eng Mater 19:1700193. https://doi.org/10.1002/adem.201700193

123. Vervaele M, De Roo B, Debehets J, Sousa M, Zhang L, Van Bilzen B, Seré S, Guillon H, Rajala M, Won Seo J et al (2017) Direct liquid injection-low pressure chemical vapor deposition of silica thin films from Di-t-Butoxydiacetoxysilane. Adv Eng Mater. https://doi.org/10.1002/adem.201700425

124. Avril L, Decams JM, Imhoff L (2013) Pulsed direct liquid injection $\mathrm{ALD} \mathrm{TiO}_{2}$ films using titanium tetraisopropoxide precursor. Phys Procedia 46:33-39. https://doi.org/10.1016/j.phpro. 2013.07.063 
125. Avril $L$, Reymond-Laruinaz $S$, Decams $J M$, Bruyère $S$, Potin $V$, de Lucas MCM, Imhoff L (2014) $\mathrm{TiO}_{2}$ anatase films obtained by direct liquid injection atomic layer deposition at low temperature. Appl Surf Sci 288:201-207. https://doi.org/10.1016/j. apsusc.2013.10.007

126. Ross AD, Gleason KK (2006) The CVD of nanocomposites fabricated via ultrasonic atomization. Chem Vap Depos 12:225-230. https://doi.org/10.1002/cvde.200506368

127. Ogawa D, Saraf I, Sra A, Timmons R, Goeckner M, Overzet L (2009) The direct injection of liquid droplets into low pressure plasmas. J Vac Sci Technol Vac Surf Films 27:342-351. https:// doi.org/10.1116/1.3081965

128. Ogawa D, Chung CW, Goeckner M, Overzet L (2010) Transient effects caused by pulsed gas and liquid injections into low pressure plasmas. Plasma Sources Sci Technol 19:034013. https://doi.org/10.1088/0963-0252/19/3/034013

129. Goeckner M, Ogawa D, Saraf I, Overzet L (2009) Progress report: direct injection of liquids into low-pressure plasmas. J Phys Conf Ser 162:012014. https://doi.org/10.1088/1742-6596/ $162 / 1 / 012014$

130. Coppins $M$ (2004) The critical droplet size in a misty plasma. In: 31 st EPS Conference on Plasma Phys. London, 28 June - 2 July 2004 ECA Vol.28G, O-2.16

131. Coppins $M(2010)$ Electrostatic breakup in a misty plasma. Phys Rev Lett. https://doi.org/10.1103/PhysRevLett.104.065003

132. Carnide G (2020) Procédé de Dépôt Couplant Un RéacteurInjecteur et Un Plasma Basse Pression - Vers Le Dépôt de Couches Minces Multifonctionnelles Pour l'aéronautique, Toulouse 3: Toulouse, France

133. Kahn M, Champouret Y, Clergereaux R, Vahlas C, Mingotaud A-F, Carnide G. Procédé de Préparation de Nanoparticules Patent No:WO 2018/019862
134. Mitronika M, Profili J, Goullet A, Gautier N, Stephant N, Stafford $\mathrm{L}$, Granier A, Richard-Plouet $\mathrm{M}(2021) \mathrm{TiO}_{2}-\mathrm{SiO}_{2}$ nanocomposite thin films deposited by direct liquid injection of colloidal solution in an $\mathrm{O}_{2} / \mathrm{HMDSO}$ low-pressure plasma. J Phys D Phys 54:085206. https://doi.org/10.1088/1361-6463/abc84d

135. Karpinski A (2011) Couches interfaciales TiO2 et NiO Déposées Pas CSD et PVD, pour cellules solaires organiques. Université de Nantes: Université de Nantes, Nantes

136. Karpinski A, Berson S, Terrisse H, Mancini-Le Granvalet $M$, Guillerez S, Brohan L, Richard-Plouet M (2013) Anatase colloidal solutions suitable for inkjet printing: enhancing lifetime of hybrid organic solar cells. Sol Energy Mater Sol Cells 116:27-33. https://doi.org/10.1016/j.solmat.2013.04.006

137. Brust M, Walker M, Bethell D, Schiffrin DJ, Whyman R (1994) Synthesis of thiol-derivatised gold nanoparticles in a two-phase liquid-liquid system. J Chem Soc Chem Commun 801-802. https://doi.org/10.1039/C39940000801

138. El Kass M, Brohan L, Gautier N, Béchu S, David C, Lemaitre $\mathrm{N}$, Berson S, Richard-Plouet $\mathrm{M}$ (2017) $\mathrm{TiO}_{2}$ anatase solutions for electron transporting layers in organic photovoltaic cells. ChemPhysChem 18:2390-2396. https://doi.org/10.1002/cphc. 201700306

139. Mitronika M, Profili J, Goullet A, Stafford L, Granier A, RichardPlouet M (2020) Modification of the optical properties and nano-crystallinity of anatase $\mathrm{TiO}_{2}$ nanoparticles thin film using low pressure $\mathrm{O}_{2}$ plasma treatment. Thin Solid Films 709:138212. https://doi.org/10.1016/j.tsf.2020.138212

Publisher's Note Springer Nature remains neutral with regard to jurisdictional claims in published maps and institutional affiliations. 